\title{
1 A secondary metabolite drives intraspecies antagonism in a gut symbiont that is inhibited
}

\section{2 by peptidoglycan acetylation}

4 Mustafa Özçam ${ }^{1,2}$, Jee-Hwan Oh${ }^{1}$, Restituto Tocmo ${ }^{1,3}$, Deepa Acharya ${ }^{4}$, Shenwei Zhang ${ }^{1}$, Silvette Ruiz-Ramírez ${ }^{1}$,

5 Fuyong $\mathrm{Li}^{5}$, Christopher C. Cheng ${ }^{6}$, Eugenio Vivas ${ }^{7}$, Federico E. Rey ${ }^{7}$, Jan Claesen ${ }^{8}$, Tim Bugni ${ }^{4}$, Jens Walter ${ }^{5,6,9,10}$,

6 Jan-Peter van Pijkeren ${ }^{1,11^{*}}$

$8 \quad{ }^{1}$ Department of Food Science, University of Wisconsin-Madison, Madison, WI, 53706, USA

$9 \quad{ }^{2}$ Division of Gastroenterology, Department of Medicine, University of California San Francisco, CA, 94141, USA.

$10{ }^{3}$ Present Address: Department of Pharmacy Practice, University of Illinois at Chicago, Chicago, IL, 60612, USA

$11 \quad{ }^{4}$ Department of Pharmacy, University of Wisconsin-Madison, Madison, WI, 53706, USA

$12{ }^{5}$ Department of Agriculture, Food and Nutritional Science, University of Alberta, Edmonton, AB T6G 2P5, Canada

$13{ }^{6}$ Department of Biological Sciences, University of Alberta, Edmonton, AB T6G 2P5, Canada;

$14 \quad{ }^{7}$ Department of Bacteriology, University of Wisconsin-Madison, Madison, WI, 53706, USA

$15{ }^{8}$ Department of Cardiovascular and Metabolic Sciences and Center for Microbiome and Human Health, Lerner

16 Research Institute, Cleveland Clinic, Cleveland, OH, 44195, USA

$17{ }^{9}$ Department of Medicine and APC Microbiome Ireland, University College Cork, Cork T12 K8AF, Ireland;

$18{ }^{10}$ School of Microbiology, University College Cork, Cork T12 YT20, Ireland.

$19 \quad{ }^{11}$ Lead Contact

$20 *$ Correspondence: vanpijkeren@wisc.edu 


\section{SUMMARY}

23 The mammalian microbiome encodes numerous secondary metabolite biosynthetic gene

24 clusters, yet their role in microbe-microbe interactions is unclear. Here, we characterized two

25 polyketide synthase gene clusters (fun and $p k s$ ) in the gut symbiont Limosilactobacillus reuteri.

26 The pks, but not the fun cluster, encodes antimicrobial activity. Forty-one out of 51 L. reuteri

27 strains tested are sensitive to Pks products, which was independent of strains' host origin. The

28 sensitivity to $\mathrm{Pks}$ was also established in intraspecies competition experiments in gnotobiotic

29 mice. Comparative genome analyses between Pks-resistant and sensitive strains identified an

30 acyltransferase gene (act) that is unique to Pks-resistant strains. Subsequent peptidoglycan

31 analysis of the wild-type and the act mutant strains showed that Act acetylates peptidoglycan.

32 The pks mutants lost their competitive advantage and act mutants lost their Pks resistance in

33 vivo. Thus, our findings provide mechanistic insights into how closely related gut symbionts can

34 compete and co-exist in the gastrointestinal tract.

39 Keywords: Limosilactobacillus reuteri, gut symbiont, polyketide, polyene, secondary

40 metabolite, biosynthetic gene clusters, acyltransferase, antimicrobial, acetylation, microbial

41 competition 


\section{INTRODUCTION}

The mammalian gastrointestinal tract is inhabited by trillions of microorganisms that coexist with their host (Sender et al., 2016). While factors like host genetics, immune status, nutritional resources and colonization history affect microbial composition (Bonder et al., 2016;

47 David et al., 2014; Hooper et al., 2015; Martínez et al., 2018; Snijders et al., 2016; Turnbaugh et al., 2009; Zarrinpar et al., 2014), the relationship between microbes is determined by competitive interactions (Boon et al., 2014). Bacteria have developed numerous strategies that mediate survival and competition, including the production of broad and narrow spectrum antimicrobials

51 (Sassone-Corsi et al., 2016). On the other hand, acquisition of resistance genes and/or

52 modification of the cell wall can help bacteria survive the antimicrobial warfare in the gut

53 (Murray and Shaw, 1997).

Some bacterial secondary metabolites have antimicrobial activity against other

55 community members. Their interactions - known as interference competition — are important in

56 the assembly and the maintenance of microbial communities (Jacobson et al., 2018). Most

57 secondary metabolites are produced by biosynthetic gene clusters (BGCs) and polyketide

58 synthase (PKS) gene clusters form a prominent subclass, involved in the biosynthesis of carbon

59 chain backbones from the repeated condensation of acyl-CoA building blocks (Lin et al., 2015;

60 Medema et al., 2014). A survey of 2,430 reference genomes from the Human Microbiome

61 Project uncovered more than 3,000 BGCs (Donia et al., 2014). So far, only seven PKS-like

62 BGCs encoded by gut-associated bacteria have been functionally characterized (Figure S1).

64 group conjugated to a polyene tail (Lin et al., 2015) and are widely distributed in soil and host-

65 associated bacteria (Cimermancic et al., 2014; Youngblut et al., 2020). Although, many polyene 
compounds isolated from terrestrial and marine microbes possess antimicrobial affects in vitro

67 (Herbrík et al., 2020; Lee et al., 2020; Li et al., 2021; Zhao et al., 2021), virtually nothing is

68 known about their ecological role in microbe-host and microbe-microbe interactions in the

69 mammalian gastrointestinal tract (Aleti et al., 2019). While metagenome studies are critically

70 important to identify novel polyene-like BGCs within the microbiome (Hiergeist et al., 2015;

71 Medema et al., 2011), the assessment of model organisms and their isogenic mutants in the

72 appropriate ecological context is critical to advance our knowledge on the biological function of

73 these BGC-derived compounds.

Limosilactobacillus reuteri, until recently known as Lactobacillus reuteri (Zheng et al.,

75 2020) is a gut symbiont species that inhabits the gastrointestinal tract of various vertebrates,

76 including rodents, birds and primates (Duar et al., 2017). This, combined with the available

77 genome editing tools (Oh and Van Pijkeren, 2014; Van Pijkeren et al., 2012; Zhang et al., 2018),

78 make L. reuteri an ideal model organism to study microbe-microbe, microbe-phage and microbe-

79 host interactions (Lin et al., 2018; Oh et al., 2019; Özçam et al., 2019; Walter et al., 2011).

80 Previously, we identified two genetically distinct PKS clusters (pks and fun) in L. reuteri R2lc

81 that activated the Aryl Hydrocarbon Receptor (Özçam and van Pijkeren, 2019).

In this study, we found that the $p k s$ cluster in L. reuteri R2lc encodes antimicrobial

83 activity. Intraspecies competition experiments in gnotobiotic mice with the wild-type and the $p k s$

84 deletion mutant revealed that Pks expression can provide a competitive advantage. Remarkably,

85 a small number L. reuteri strains were resistant to the antimicrobial activity of Pks. We

86 discovered this resistance was driven by a gene encoding an acetyltransferase gene that increases

87 peptidoglycan acetylation. Thus, our findings uncovered mechanisms by which gut symbionts 
88 can compete and co-exist with closely related strains through secondary metabolite production

89 and cell-wall modification.

\section{$91 \quad$ RESULTS}

\section{L. reuteri Pks inhibits the competitor strain}

93 The rodent isolate L. reuteri R21c contains two PKS clusters, fun and pks (Figure 1A). In

94 both the human and rodent gut ecosystem, L. reuteri R21c outcompetes most L. reuteri strains,

95 including the rodent isolate L. reuteri 100-23 (Duar et al., 2017; Oh et al., 2009). Because select

96 PKS products have antimicrobial activity (Lin et al., 2015), we tested to what extent Pks and Fun

97 provide strain R2lc with a competitive advantage. We performed in vitro competition

98 experiments in batch cultures using 1:1 mixtures of the rodent gut isolates L. reuteri 100-23 and

99 L. reuteri $\mathrm{R} 2 \mathrm{lc}$ wild type, or our previously generated $\mathrm{PKS}$ mutants (R21c $\Delta$ fun or $\mathrm{R} 2 \mathrm{lc} \Delta p k s)$

100 (Özçam et al., 2019). Following 24 hours of incubation, the mixed cultures were plated. On agar,

101 R2lc and its derivatives form pigmented colonies, while 100-23 colonies are opaque color in

102 appearance. Co-incubation of $\mathrm{R} 21 \mathrm{c}+100-23$ or $\mathrm{R} 2 \mathrm{lc} \Delta$ fun $+100-23$ only recovered pigmented

103 colonies; however, co-incubation of R2lc $\Delta p k s+100-23$ yielded a mixture of pigmented and

104 opaque colonies (\% pigmented:opaque colony distribution is 29:71) (Figure 1B). These data

105 suggest that R2lc pks but not fun cluster provides strain R2lc with a competitive advantage when

106 co-cultured with $L$. reuteri 100-23. 

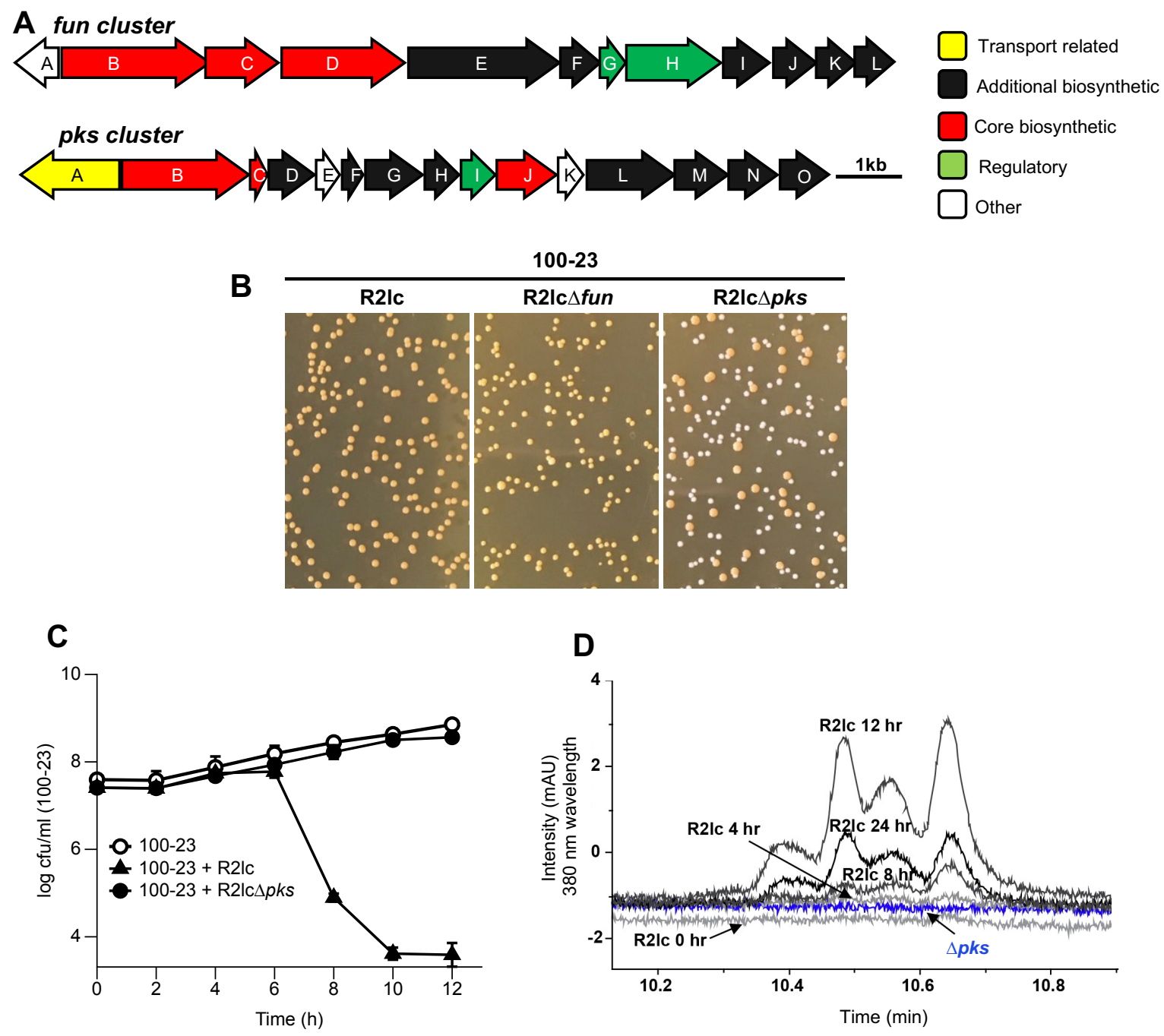

109 Figure 1. A polyketide synthase cluster in L. reuteri R2Ic produces polyene-like compounds

110 and provides competitive advantage A) The fun cluster (top) spans $13.4 \mathrm{~kb}$ containing 12 Open

111 Reading Frames (ORFs), and the pks cluster (bottom) spans $11.3 \mathrm{~kb}$ containing 15 ORFs.

112 Transport-related, additional biosynthetic, regulatory, and other genes are represented by

113 different colors. B) R2lc and R2lc $\Delta$ fun but not R2lc $\Delta p k s$ inhibits L. reuteri 100-23. C) R2lc has

114 bactericidal effect against 100-23. Single culture $\left(\mathrm{OD}_{600}=0.1\right)$ or co-cultures $\left(\mathrm{OD}_{600}=0.05\right.$ from

115 each strain) were mixed and incubated in MRS broth $\left(\mathrm{pH}: 4.0,37^{\circ} \mathrm{C}\right)$ and samples were collected 
116 every two hours for up to 12 hours. The data represents the average of three independent

117 experiments. Error bars represents standard deviation. D) UPLC-PDA-MS analysis of R21c and

$118 \Delta p k s$ mutant. R21c but not $\Delta p k s$ produces unique compounds with a maximum absorption of

119 380nm (Black: R2lc, blue: $\Delta p k s$ ). See also Figure s3.

\section{L. reuteri Pks has a time-dependent bactericidal effect}

To understand the dynamics by which R2lc outcompetes 100-23, we performed a time

123 course competition experiment in batch cultures. Mixtures $\left(1: 1, \mathrm{OD}_{600}=0.05\right.$ per strain $)$ were

124 prepared of R2lc $+100-23$, and R2lc $\Delta p k s+100-23$. As a control, a monoculture of 100-23 was

125 grown. We harvested samples every two hours and determined the CFU levels. Up to six hours,

126 mixtures of R2lc $+100-23$ and R2lc $\Delta p k s+100-23$ yielded similar levels of 100-23 colonies,

127 which were comparable to the levels obtained when 100-23 was cultured independently.

128 However, after eight and ten hours of co-incubation of R2lc $+100-23,100-23$ CFU levels were

129 reduced by three and five orders of magnitude, respectively, while 100-23 continued to grow in

130 the R2lc $\Delta p k s+100-23$ mixture (Figure 1C). Importantly, the sharp decline in 100-23 CFU

131 counts suggests Pks elicits a strong bactericidal activity against 100-23. Also, the fact that killing

132 of 100-23 is initiated after 6-hours of co-culture suggests that production of Pks may be growth

133 phase dependent.

134 In mice, L. reuteri - including strain 100-23 - form a biofilm on the stratified squamous

135 epithelium of the forestomach (Frese et al., 2013; Lin et al., 2018; Savage et al., 1968). Cell

136 numbers of 100-23, R2lc or R2lc $\Delta p k s$ in gastric biofilms were similar $\left(4.3 \times 10^{8} \pm 2.6 \times 10^{8}\right.$,

$1372.0 \times 10^{8} \pm 3.0 \times 10^{7}, 1.7 \times 10^{8} \pm 4.1 \times 10^{7} \mathrm{CFU} / \mathrm{ml}$, respectively) (Figure s2A). In biofilm co-

138 cultures, however, R21c was 750-fold more abundant than 100-23 $(P=0.002)$. The ability of 
R21c to outcompete 100-23 in biofilm is mediated by Pks, because co-incubation of R2lc $\Delta p k s$ with 100-23 recovered similar levels of CFUs for both strains $(P=0.27)$ (Figure s2B).

\section{L. reuteri pks cluster produces unique polyene-like compounds}

144 Performance Liquid Chromatography coupled with Photodiode Array and Mass Spectrometer

145 (UPLC-PDA-MS) analysis. By comparing the chromatograms obtained from R2lc and R2lc $\Delta p k s$

146 cultures, we found that R2lc produces a family of unique compounds with a maximum

147 wavelength of $380 \mathrm{~nm}$. These compounds eluted towards the end of the gradient run where the

148 solvent composition was close to $100 \%$ methanol, indicating a hydrophobic characteristic. The

149 large retention time of the compounds on the C18 column and the maximum absorption

150 wavelength are consistent with previously identified polyene compounds (Gruber and Steglich,

151 2007). Therefore, the putative products of the $p k s$ cluster are predicted to be polyene compounds.

152 The UV chromatogram extracted from the R2lc culture at different time points shows an

153 increase in the production of these compounds up to 12 hours of incubation, after which the

154 intensity reduces as shown in samples at 24 hours (Figure 1D). We subsequently analyzed the

155 Liquid Chromatography-Mass Spectrometry (LC-MS) data of R2lc and $\Delta p k s$ samples collected

156 above to identify the polyene products produced by R2lc. The mass spectrum of the peak

157 between $10.52 \mathrm{~min}-10.58 \mathrm{~min}$ in the R2lc chromatogram at 12 hours clearly showed an ion

158 with $m / z[\mathrm{M}+\mathrm{H}]^{+}$value of 257.1172 and corresponding $m / z[\mathrm{M}+\mathrm{Na}]^{+}$value of 279.0092, which

159 were absent in the 12-hour culture of $\Delta p k s$ (Figure s3). The high-resolution mass for the

160 compound led to the predicted molecular formula of $\mathrm{C}_{16} \mathrm{H}_{16} \mathrm{O}_{3}$. The reduction of Pks compounds

161 after 12 hours of incubation suggests instability of Pks molecules in our experimental setup. 
162 Taken together, these data suggest that antibacterial compounds are released in a time-dependent

163 manner.

\section{L. reuteri Pks molecules provide a competitive advantage in vivo}

167 cluster in vivo, we gavaged germ-free mice ( $\mathrm{n}=4$ /group) with a 1:1 mixture of $\mathrm{R} 21 \mathrm{c}+100-23$, or

$168 \mathrm{R} 2 \mathrm{lc} \Delta p k s+100-23$. To quantify each strain in the fecal material, we engineered R2lc and its

169 derivatives to encode chloramphenicol resistance (R21c::Cm and R2lc $\Delta p k s:: C m$ ) while strain

170 100-23 was rifampicin-resistant (100-23- Rif $\left.^{\mathrm{R}}\right)$. We determined the competition ratio between

171 R21c and 100-23 (competition ratio: R2lc CFU count/competitor strain's CFU count) over a

172 period of six days in feces. We found that L. reuteri R2lc wild-type but not the $\Delta p k s$ mutant

173 gradually outcompetes the 100-23 strain. The R21c:100-23 competition ratio increased from

174 107:1 (day 1) up to 980:1 (day 6), while the competition ratio between R21c $\Delta p k s: 100-23$

175 declined from 35:1 (day 1) to 4:1 (day 6) (Figure 2A). Similarly, the R21c:100-23 competition

176 ratio was higher than the R2lc $\Delta p k s: 100-23$ competition ratio in the forestomach (31,973-fold vs

177 7,8-fold, $P=0.03$ ), cecum (1,515-fold vs. 2.9-fold, $P=0.03)$, colon (1,474-fold vs. 8.9-fold, $P=$

$1780.03)$ and jejunum $(1,114$-fold vs. 5.2-fold, $P=0.03)$ (Figure 2B). Thus, our findings

179 demonstrate that Pks provides L. reuteri R2lc with a competitive advantage throughout the

180 murine intestinal tract.
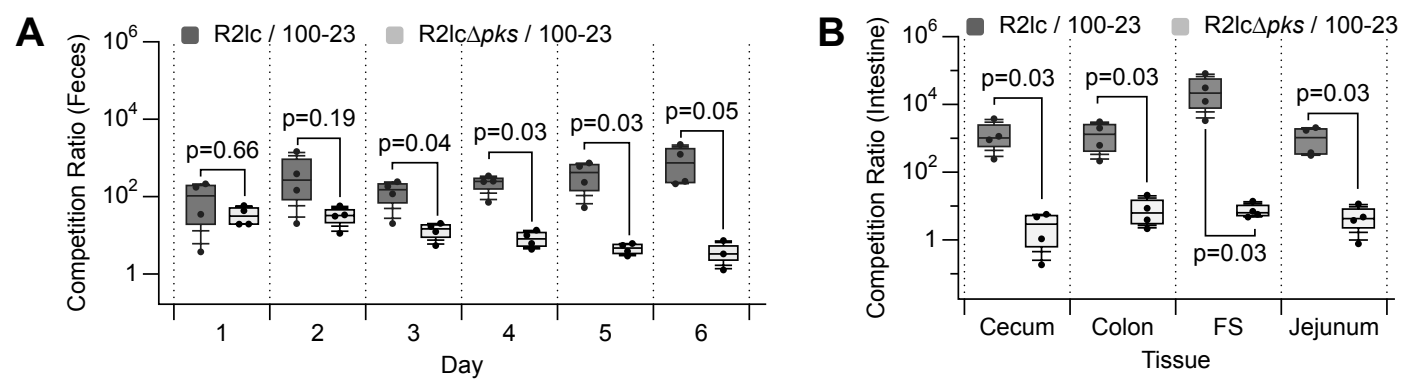
182 Figure 2. L. reuteri Pks molecules provide a competitive advantage in vivo.

183 A 1:1 mixture of R2lc $+100-23$, or R2lc $\Delta p k s+100-23$ was administered by oral gavage to germ-

184 free mice. A) Competition ratios of the indicated strains in fecal and B) intestinal content (day 6)

185 were determined. In box and whisker plots, the whiskers represent the maximum and minimal

186 values, and the lower, middle and upper line of the box represent first quartile, median and third

187 quartile, respectively. Circles represent data from individual mouse. Statistical significance was

188 determined by Wilcoxon / Kruskal-Wallis Tests $\mathrm{p}<0.05$ considered as significant. $\mathrm{p}=\mathrm{P}$ value.

189 F.S.: Forestomach.

190

\section{L. reuteri Pks-mediated antimicrobial effect is strain specific}

Now we established that L. reuteri Pks provides an in vivo and in vitro competitive

193 advantage against strain 100-23, we next investigated to what extent Pks-mediated killing is

194 strain specific. We performed in vitro competition experiments with 51 L. reuteri gut isolates

195 from different host origins: human, rat, mouse, chicken and pig. To quantify strains, we used

196 derivatives of R2lc and R2lc $\Delta p k s$ that were engineered to be chloramphenicol resistant. For each

197 competitor strain we isolated a natural rifampicin-resistant mutant. Strain R21c and the

198 competitor strain were mixed 1:1 in MRS medium adjusted to $\mathrm{pH} 4.0$, which is $\mathrm{pH}$ of the

199 forestomach, the natural habitat of strain R21c. The co-cultures were incubated for 24 hours, and

200 appropriate dilutions were plated on MRS plates containing chloramphenicol ( $5 \mu \mathrm{g} / \mathrm{ml}$, for R21c

201 and R2lc $\Delta p k s)$ or rifampicin $(25 \mu \mathrm{g} / \mathrm{ml}$, for competitor strain). Competition ratios were

202 determined after 24 hours of incubation.

203 Based on non-parametric statistical tests, we identified that R21c inhibits 41 out of 51

$204(80.4 \%)$ L. reuteri strains. Specifically, six out of nine $(66.6 \%)$ rat-isolates, seven out of ten 
205 (70\%) mouse isolates, 16 out of $18(89 \%)$ pig isolates, eight out of nine $(88.9 \%)$ chicken isolates

206 and two out of five (40\%) human isolates were significantly inhibited by R21c (R2lc vs

207 competitor CFU, $P<0.05$ ). To test if the competitive advantage of R2lc is driven by Pks, we

208 repeated the competition experiments with R2lc $\Delta p k s$. We found that deletion of the $p k s$ cluster

209 resulted in loss of antimicrobial activity and the $\Delta p k s$ mutant did not show strong inhibition

210 against competitor strains. However, $\Delta p k s$ mutant still inhibited some competitor strains (16 out

211 of 51) to a small extent, with observed differences in Colony Forming Units (CFUs) between

$212 \Delta p k s$ and competitor strains less than two orders of magnitude (Figure 3). These data

213 demonstrate that R2lc-Pks mediated antimicrobial effect is strain specific and 10 out of 51 tested

214 L. reuteri strains (19.6\%) are not inhibited/outcompeted by the Pks producing strain.

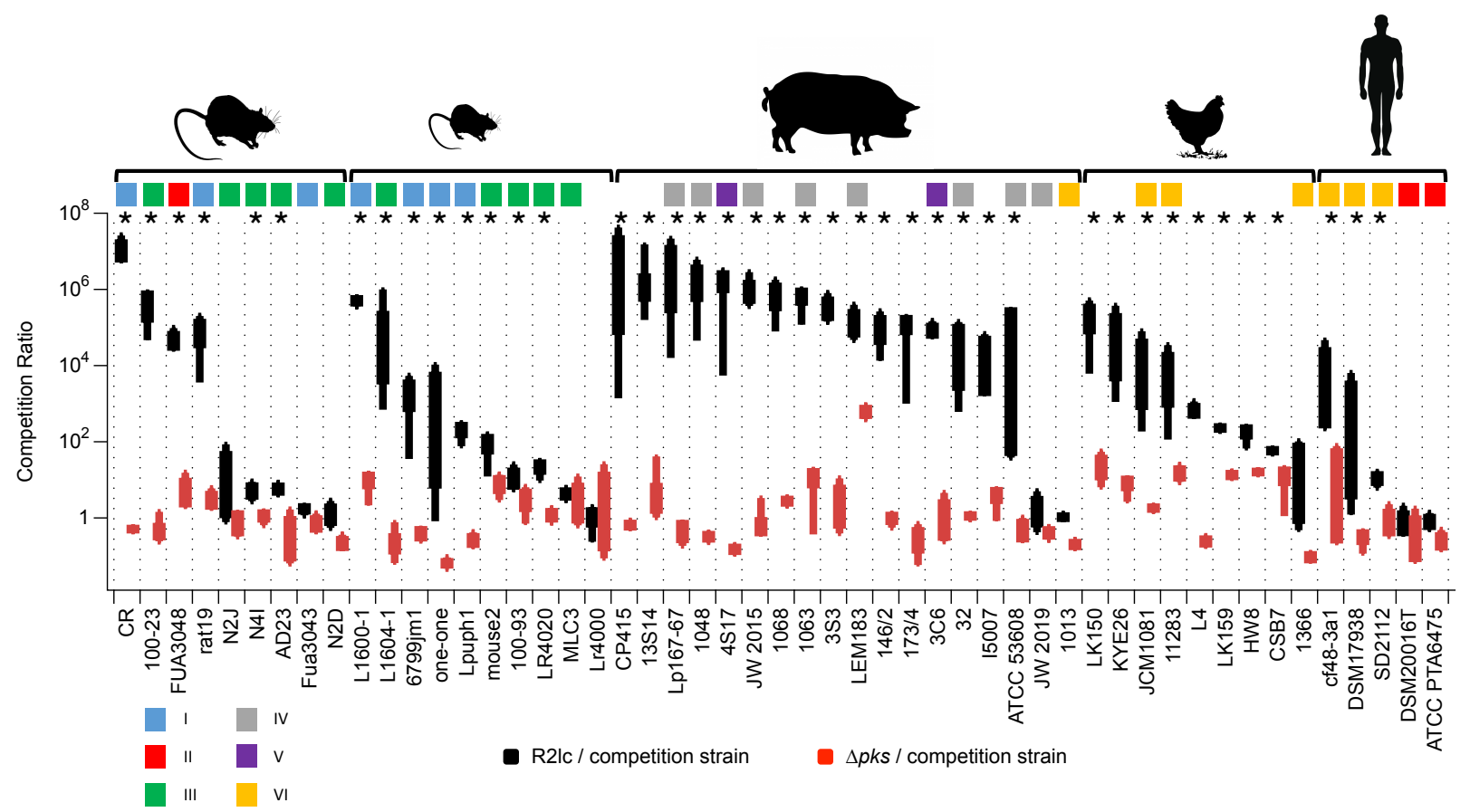

216 Figure 3. In vitro competition ratio of $L$. reuteri R2Ic and R2Ic $\Delta p k s$ with a panel of 51

217 L. reuteri strains from different host origin. Competition ratios between R2lc and the

218 competitor strain (black) and R2lc $\Delta p k s$ and the competitor strain (red) after 24h co-incubation in

219 MRS (pH 4.0). Data shown are based on at least three biological replicates. The whiskers 
220 represent the maximum and minimal values, and the lower, middle and upper line of the box

221 represent first quartile, median and third quartile, respectively. Host origin (top) and the $L$.

222 reuteri phylogenetic lineage (color coding) are indicated. Statistical significance was determined

223 by Wilcoxon / Kruskal-Wallis Tests. Asterisks (*) represents statistical significance between

224 R2lc vs competitor strain for the top panel ( $p<0.05$ considered as significant). See also Table S3.

\section{L. reuteri strains resistant to Pks encode an acyltransferase enzyme}

Next, we aimed to understand what the underlying mechanism is that allows select strains

228 to be resistant to L. reuteri $\mathrm{R} 2 \mathrm{lc}$ Pks. We performed comparative genome analyses to identify

229 genes unique to strains that are resistant to L. reuteri R21c Pks. We included 24 genome

230 sequences in our analyses, of which four genome sequences were derived from resistant strains

231 (mlc3, Lr4000, 6475 and 20016 ${ }^{\mathrm{T}}$ ) (Table S1). Our initial genome comparison analyses revealed

232 eight genes unique to three of the four R2lc-resistant strains (mlc3, 6475 and 20016 ${ }^{\mathrm{T}}$ ) (Table S2).

233 One of the eight unique genes (act, Lreu_1368 in strain DSM20016 ${ }^{\mathrm{T}}$, Table S2) is

234 annotated as an O-acyltransferase. This gene became our focus as several studies demonstrated

235 that deletion of homologous act genes reduces the resistance to enzymes that target the

236 peptidoglycan cell wall in other Gram-positive bacteria (reviewed in (Ragland and Criss, 2017)).

237 Moreover, resistance to antimicrobial molecules is typically associated with altered cell-wall

238 peptidoglycan structures (Vollmer, 2008). In L. reuteri, the act gene is located in the surface

239 polysaccharide (SPS) gene cluster. Based on the available genome sequences, we found that

240 three resistant strains (mlc3, 6475 and $20016^{\mathrm{T}}$ ) all putatively encode a nearly identical Act

241 protein ( $\geq 99 \%$ amino acid identity). Three R21c-Pks-sensitive strains (CR, ATCC 53608 and

242 one-one) putatively encode a distinct Act protein with 54\% amino acid identity to the predicted 
243 Act amino acid sequence of resistant L. reuteri strains. Six additional R2lc-Pks-sensitive strains

244 (I5007, 6799jm-1, lpup, CF48-3A1, Lr4020 and SD2112) putatively encode Act with 26-28\%

245 amino acid identity compared to the predicted Act amino acid sequence of resistant L. reuteri

246 strains. The remainder of the 12 strains that are sensitive to R2lc-Pks do not contain the act gene

247 in the SPS gene cluster (Figure 4). 


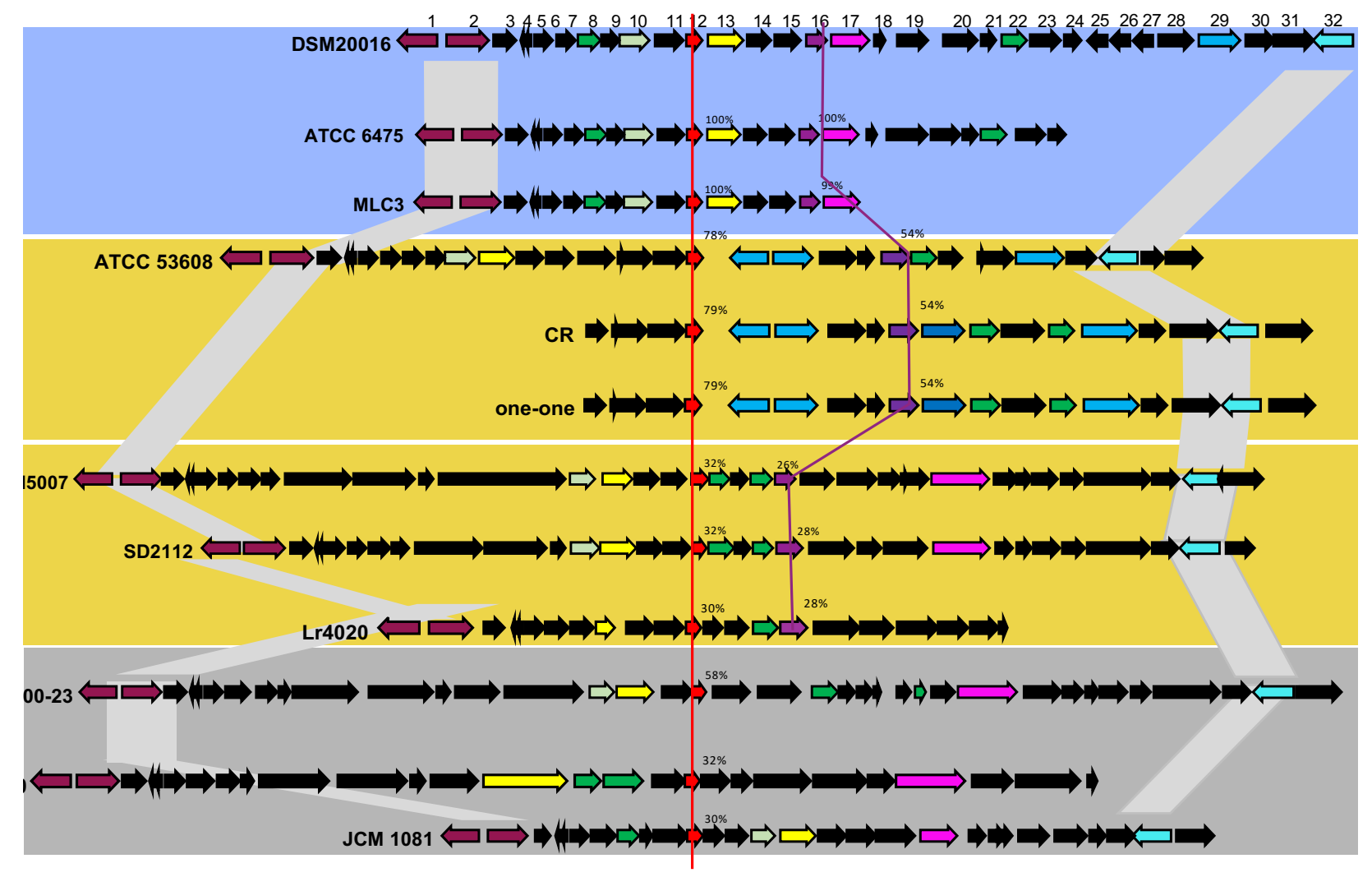

Ipsular polysaccharide biosynthesis $\square$ UDP-galactopyranose mutase $\square$ Acyltransferase $\begin{aligned} & \text { Membrane protein involved in the } \\ & \text { export of O-antigen and teichoic } \\ & \text { acid }\end{aligned}$
anscription attenuator

Arginine:ornithine antiporter, APA family

17. Mannosyl-glycoprotein endo-beta-N-acetylglucosamidase

Amino acid/polyamine/

Hypothetical protein

Hypothetical protein

Regulatory protein $\operatorname{RecX}$

Hypothetical protein

Glycosyl transferase, family 2

Undecaprenyl-phosphate galactose phosphotransferase

j. UDP-galactopyranose mutase

1. Hypothetical protein

2. Lipopolysaccharide biosynthesis protein

3. Membrane protein involved in the export of O-antigen, teichoic acid

18. Transposase IS200-family protein

19. N-acetylmuramoyl-L-alanine amidase, family 2

20. NLP/P60 protein

21. Hypothetical protein

22. Glycosyl transferase, family 2

23. Integrase, catalytic region

24. stB domain protein ATP-binding protein

25. Transposase InsO

26. Hypothetical protein

27. Transposase and inactivated derivatives IS30

28. Hypothetical protein

29. Dextransucrase

30. Protein of unknown function IJPF0118

\section{Figure 4. Variability in gene content of Surface Polysaccharide gene cluster in L. reuteri.}

254 Comparison of surface polysaccharide (SPS) gene clusters of strains resistant and sensitive to

255 R2lc-Pks. Strains \#1-3 (resistant) each putatively encode a nearly identical Act protein with

$256 \geq 99 \%$ amino acid identify; strains \#4-6 (sensitive) putatively encode Act that shares $54 \%$ amino

257 acid identity to Act of resistant strains; strains \#7-9 (sensitive) putatively encode Act that shares 
258 25-28\% amino acid identity to Act of resistant strains; strains \#10-12 (sensitive) lack the act

259 gene. Genes are color-coded with their predicted functions based on the annotation of the SPS

260 gene cluster in L. reuteri DSM20016 ${ }^{\mathrm{T}}$. See also Table S1 and Table S2.

263 phylogenetic tree of Act amino acid sequences from 133 L. reuteri strains. We found that 43 out

264 of 133 strains (32.3\%) contain an act gene whose putative product shares 99-100 amino acid

265 identity to the predicted amino acid sequence of resistant L. reuteri strains, while the remaining

266 strains putatively encode Act with 23-72\% amino acid identity (Figure 5). Also see Table S6. 




268 Figure 5. Phylogenetic tree of L. reuteri Act homologs. We constructed a phylogenetic tree

269 based on Act amino acid sequences derived from 133 Act encoding L. reuteri strains to predict

270 R21c-resistance and sensitive strains. Fourty-three out of 133 strains $(32.3 \%)$ encode and act

271 gene that shares 99-100 amino acid identify with the act gene in ATCC 6475 strain, thus, 
272 predicted to be R2lc-resistant (blue ring). The remaining strains encode an act gene that shares

273 23-54\% amino acid identify with the act gene in PTA 6475 (yellow ring). See also Table S6.

274

275

276

277

278

279

280

281

282

283

284

285

286

287

288

289

290

291

292

293

294

295

\section{The acyltransferase gene in $L$. reuteri confers protection to R2lc-Pks products}

To test if the act gene confers protection to R2lc-Pks products, we generated act mutants in three L. reuteri strains: mlc3 (rat isolate, clade I), ATCC 6475 (human isolate, clade I), and DSM17938 (human isolate, clade III). In each of these strains, inactivation of act increased the sensitivity to R2lc-Pks, as is evident from the increased competition ratios between R2lc vs $\Delta a c t$ compared to the competition ratios between R2lc vs wild-type strain (Figure 6A). In contrast, the competition ratios between $\mathrm{R} 2 \mathrm{lc} \Delta p k s$ vs L. reuteri $\Delta a c t$ strains are across the board lower compared to the competition ratios of R2lc vs $\Delta a c t$ strains (Figure 6B). Overall, our data showed that the act gene in L. reuteri confers protection to R2lc-Pks products.

\section{L. reuteri Act provides resistance against antimicrobial Pks molecules in vivo}

To determine to what extent the act gene protects against R2lc Pks in vivo, we performed competition experiments in mice. Germ-free mice were administrated with a 1:1 mixture of any of the following strain combinations: R2lc $\pm p k s$ and mlc3 \pm act (Figure 6BC). Following administration, fecal samples were analyzed at day one, three and six, and animals were sacrificed at day 7 after which we analyzed microbial counts in the stomach, jejunum, cecum and colon. Fecal analyses revealed that the competition ratios between $\mathrm{R} 2 \mathrm{lc}$ and mlc3 or its isogenic $\Delta a c t$ mutant were comparable $(P>0.05)$; however, at day 7 , the competition ratio of R21c:mlc3 $\Delta a c t$ was significantly larger compared to R2lc:mlc3 $(2,183 \pm 3,060$-fold vs $95 \pm$ 58-fold, respectively; $P<0.01$ ). We also observed that in all intestinal tissues the competition ratio of R21c::mlc3 $\Delta$ act was larger compared to R21c::mlc3. Specifically, forestomach $(3,777 \pm$ 
2,259-fold vs $31 \pm 48$-fold; $P<0.01)$, jejunum $(9,510 \pm 15,239$-fold $v s 62 \pm 55$-fold; $P<0.01)$, cecum $(9,872 \pm 17,683$-fold vs $115 \pm 99$-fold; $P<0.01)$, colon $(959 \pm 4,703$-fold $v s 118 \pm$

298 104-fold; $P<0.01)$. Thus, the act gene provides protection against R2lc-Pks in vivo. To test to

299 what extent R2lc Pks provides R2lc with a competitive advantage in these experiments, we

300 performed competition experiments with R2lc $\Delta p k s:$ mlc3 and R2lc $\Delta p k s:$ :mlc3 $\Delta a c t$ (Figure 6C).

301 Overall, the competition ratios of R2lc $\Delta p k s:: \operatorname{mlc} 3$ and R2lc $\Delta p k s: \operatorname{mlc} 3 \Delta a c t$ are lower compared 302 to the competition ratios observed with R2lc wild-type, which demonstrates a clear role for Pks

303 in providing R21c with a competitive advantage in vivo. Interestingly, the R21c $\Delta p k s: \mathrm{mlc} 3 \Delta a c t$

304 competition ratio is higher than that of R2lc $\Delta p k s:$ :mlc3 in the stomach (1.5-fold vs 0.5 -fold, $P=$ 305 0.02), jejunum (2.2-fold vs 0.5-fold, $P=0.01)$ and cecum (2.2-fold vs 1.2 -fold, $P=0.04)$

306 (Figure 6C) which might be due to the role of act gene in lysozyme resistance during in vivo 307 colonization. 

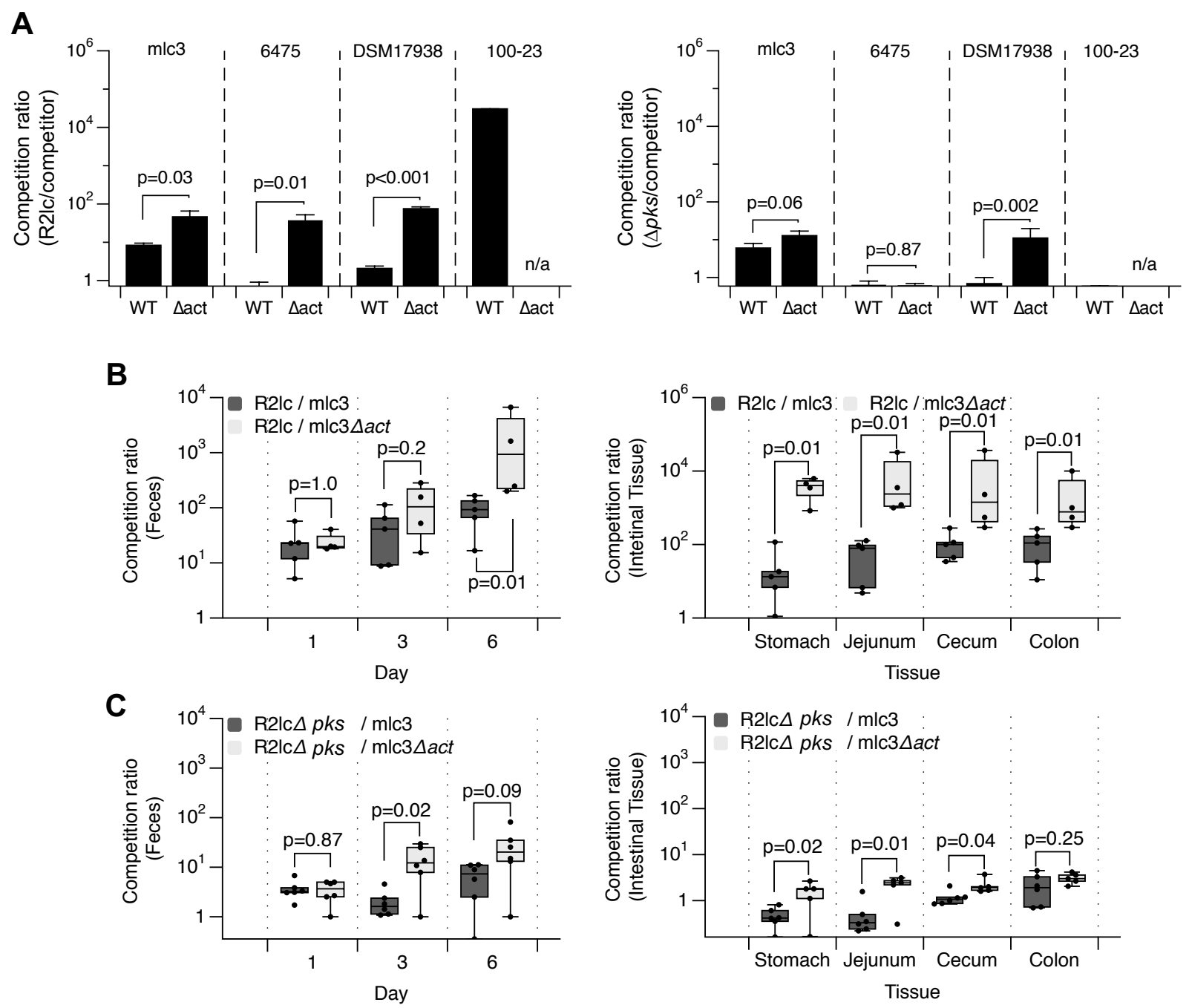

Figure 6. The act acyltransferase gene protects against R2lc-Pks molecules. A) Act provides

310 resistance to R2lc-mediated killing (left panel), which is mediated by the inhibitory activity of an

311 intact Pks (right panel). B and C) Competition ratios of the indicated strains in the previous

312 germ-free mice in fecal (left panel) and intestinal contents (right panels). When data are

313 presented as box and whisker plots, the whiskers represent the maximum and minimal values,

314 and the lower, middle and upper line of the box represent first quartile, median and third quartile,

315 respectively. Points represent individual data points. Statistical significance was determined by

316 Wilcoxon / Kruskal-Wallis Tests, $\mathrm{p}=\mathrm{P}$ value. $\mathrm{P}<0.05$ considered significant. 


\section{The acyltransferase gene increases peptidoglycan acetylation} peptidoglycan (PG) (Moynihan and Clarke, 2010). To understand the role of act gene on $L$. reuteri peptidoglycan acetylation, we performed HPLC analyses to determine PG acetylation content. Analysis of cell wall extracts derived from L. reuteri 100-23, a Pks-sensitive strain which does not encode Act, revealed that $6.65 \pm 1.19 \%$ was acetylated relative to total MurN. Next, we cloned the act gene from strain mlc3 in the inducible expression vector pSIP411, which was established in strain 100-23. Induced expression of act in 100-23 increased the relative

327 peptidoglycan acetylation to $28.7 \pm 9.0 \%$. Inactivation of act in L. reuteri strains resistant to 328 R2lc-Pks reduced peptidoglycan acetylation levels: from $70.1 \pm 4.9 \%$ to $2.3 \pm 0.3 \%$ for mlc3;

329 and from $61.2 \pm 9.1 \%$ to $21.3 \pm 12.9 \%$ for 6475$)$. Overexpression, of act gene in mlc $3 \Delta a c t$ and

$3306475 \Delta a c t$ restored the relative PG acetylation (from $2.3 \pm 0.3 \%$ to $\%$ to $51.8 \pm 15.1 \%$ for mlc3 $\Delta a c t:: a c t$; and from $21.3 \pm 12.9 \%$ to $50.9 \pm 9.2 \%$ for $6475 \Delta a c t:: a c t$ ) (Table 1$)$. Together

332 these data suggests that act gene in L. reuteri is responsible for increased peptidoglycan

333 acetylation, which is linked to the resistance to antimicrobial polyketides produced by R2lc.

Table 1. O-acetylation levels were determined by base-catalyzed hydrolysis and release of acetate. Percent $\mathrm{O}$-acetylation is reported relative to muramic acid (MurN) content.

\begin{tabular}{ll}
\hline Strain & \% O-acetylation \\
\hline $100-23$ & $6.65 \pm 1.19$ \\
$100-23+$ pSIP control & $3.46 \pm 0.07$ \\
$100-23:: a c t$ & $28.70 \pm 9.01$ \\
mlc3 & $70.12 \pm 4.85$ \\
mlc3 $\Delta a c t+$ pSIP control & $2.31 \pm 0.29$ \\
mlc3 $\Delta a c t:: a c t$ & $51.76 \pm 15.09$ \\
6475 & $61.21 \pm 9.07$ \\
$6475 \Delta a c t+$ pSIP control & $21.29 \pm 12.92$ \\
$6475 \Delta a c t:: a c t$ & $50.90 \pm 9.18$ \\
\hline
\end{tabular}

$337{ }^{a}$ Results are from one representative biological replicate measured in triplicate and reported as 338 mean with Standard Deviation. 


\section{Discussion}

In this study, we provide mechanistic insight into intra-species antagonism based on a

342 secondary metabolite in the gut symbiont L. reuteri. We discovered that a biosynthetic gene

343 cluster (BGC) provides a competitive advantage in the gastrointestinal tract by killing closely

344 related microbes in a strain-specific manner. Expression of the peptidoglycan acetylating enzyme

345 Act by select strains of L. reuteri provides protection against this killing activity.

Closely related strains that occupy the same niche are subject to fierce competition

347 (Hibbing et al., 2010). While the co-existence of two closely related strains may be stable in the

348 host, long-term evolution may lead to different ecological outcomes (Edwards et al., 2018).

349 Either evolution leads to changes that form a more stable population-lineages are overall less

350 competitive - or evolution results in increased fitness of one lineage. The lineage with increased

351 fitness will replace the competing lineage, or the competing lineage may evolve in a way that

352 will allow it to persist (Le Gac et al., 2012). Our findings are interesting in light of these

353 ecological theories. Specifically, four distinct lineages have thus far been identified among

354 rodent L. reuteri isolates (Frese et al., 2011). Our competition analyses revealed that nearly all

355 strains in lineage I are sensitive to R2lc-Pks products while most strains in lineage III are

356 resistant. One potential explanation for the latter is the broad distribution of nearly identical act

357 genes in L. reuteri strains from different host origin (Figure 5, blue ring), which suggests act

358 exerts an evolutionary pressure that will increase the fitness in the gut ecosystem. The findings

359 presented in this work, the observation that aryl polyene gene clusters are widely distributed

360 throughout the host-associated bacteria (Cimermancic et al., 2014), and that L. reuteri 6475 $\Delta a c t$

361 has reduced gastrointestinal survival (preliminary data) support the importance of Act in gut 
362 fitness and make it collectively less likely that act is acquired through a neutral process such as 363 genetic drift.

364 The evolution of a vertebrate symbiont with its host might be reciprocal, resulting in co-

365 evolution. The beneficial traits that a microbe exerts on its host may have been shaped by natural

366 selection as they promote host fitness, which is critical for the microbe to thrive in its niche.

367 R2lc-Pks molecules activates the aryl-hydrocarbon receptor (AhR), a ligand activated

368 transcription factor (Özçam et al., 2019). Activation of AhR has been shown to induce

369 production of interleukin-22 (IL-22) (Veldhoen et al., 2008), which enhances the innate immune

370 response by inducing antimicrobial peptides (i.e. Reg3-lectins) production from the mucosal

371 layer (Vaishnava et al., 2011; Zheng et al., 2008). It is intriguing to speculate that Pks molecules

372 provide R2lc with additional, host-mediated competitive advantage by killing competitors, which

373 may be aided by Pks-mediated AhR activation that leads to antimicrobial peptide production by

374 the host. Collectively, this would support the coevolution between select microbes and their host.

375 This work contributes to our understanding of the ecological role of a gut symbiont-

376 encoded secondary metabolite and provides mechanistic insight into how closely related strains

377 developed resistance against these antimicrobial molecules by acetylation of the cell-wall

378 peptidoglycan. It is plausible bacteria have evolved other mechanisms to survive exposure to

379 Pks. In this work, we did encounter one strain — the rodent isolate Lr4000 — that does not encode

380 Act but was resistant to R2lc Pks molecules during the batch culture competition experiments

381 and the mechanism of resistance remains to be elucidated.

382 With a number of genome editing tools available for L. reuteri, we are in a position to use

383 genetic approaches to study microbe-microbe interactions in a gut symbiont. When these

384 experiments are placed in the right ecological context, mechanistic insight can be provided on 
385 the formation and stability of microbial communities, which is expected to provide insight how

386 microbial diversity is maintained within complex ecosystems. This knowledge can be leveraged

387 to provide rational approaches to select probiotics and next-generation probiotics to ultimately

388 promote animal and human health. 


\section{ACKNOWLEDGEMENTS}

We thank Siv Ahrné (Lund University, Sweden) for providing L. reuteri R21c, N2J, N2D,

391 and N4I, BioGaia AB (Stockholm, Sweden) for providing L. reuteri strains ATCC PTA 6475, and

392 Joseph Skarlupka for technical assistance. We are grateful to the College of Agricultural Life

393 Sciences (CALS) Statistical Consulting Lab for their assistance in the statistical analysis. This

394 work was supported by startup funds from the University of Wisconsin-Madison to J.P.V.P., the

395 UW-Madison Food Research Institute, and the United States Department of Agriculture, National

396 Institute of Food and Agriculture (USDA NIFA) Hatch award MSN185615 and grant no. 2018-

397 6717-27523. M.Ö. received financial support from the Turkish Ministry of National Education,

398 from the Department of Food Science, and is the recipient of the Robert H. and Carol L. Deibel

399 Distinguished Graduate Fellowship in Probiotic Research, which is awarded by the Food Research

400 Institute (UW-Madison). J.C. is supported by National Institutes of Health grant R01 AI153173.

401 Gnotobiotic work was partly supported by the Office of the Vice-Chancellor for Research and

402 Graduate Education at the University of Wisconsin-Madison, with funding from the Wisconsin

403 Alumni Research Foundation.

404

\section{AUTHOR CONTRIBUTIONS}

M.Ö. designed and performed the experiments, analyzed and interpreted the data, and

407 wrote and revised the manuscript. J.-H.O., R.T., D.A., S.Z., C.C., E.V., performed experiments,

408 provided technical support, S.R.R., J.S., performed experiments. T.B., J.C., J.W. shared resources

409 contributed to data interpretation and revised the manuscript; J.P.v.P. secured funding, conceived,

410 designed, and supervised the study, and critically revised the manuscript. 


\section{DECLERATION OF INTEREST}

413 JPVP received unrestricted funds from BioGaia, AB, a probiotic-producing company.

414 JPVP is the founder of the consulting company Next-Gen Probiotics, LLC. JW has received

415 grants and honoraria from several food and ingredient companies, including companies that

416 produce probiotics. JW is a co-owner of Synbiotic Solutions, LLC, and is on the Scientific

417 Advisory Board of Alimentary Health. M.Ö. was an employee of DuPont Nutrition and

418 Biosciences. JC is a Scientific Advisor for Seed Health, Inc.

420 STAR METHODS

421 RESOURCE AVAILABILITY

422

\section{Lead contact}

424 Further information and requests for resources should be directed to and will be fulfilled by the 425 Lead Contact, Jan-Peter van Pijkeren (vanpijkeren@wisc.edu).

\section{Material Availability}

428 Requests for the plasmids and strains used in this study should be directed to and will be fulfilled 429 by the Lead Contact, Jan-Peter van Pijkeren (vanpijkeren@wisc.edu).

\section{Data and Code Availability}

432 Any additional information required to reanalyze the data reported in this paper is available from 433 the lead contact upon request. 
KEY RESOURCE TABLE

\begin{tabular}{|c|c|c|}
\hline REAGENT or RESOURCE & SOURCE & IDENTIFIER \\
\hline \multicolumn{3}{|l|}{ Bacterial strains } \\
\hline \multicolumn{3}{|c|}{ See Table S3 for bacterial stains used in this study } \\
\hline \multicolumn{3}{|l|}{ Chemicals } \\
\hline Agar & Alfa & Cat\#A10752 \\
\hline Agarose & IBI & Cat\# IB70042 \\
\hline LB broth & Acumedia, Neogen & Cat\# 7290A \\
\hline MRS broth & $\mathrm{BD}$ & Cat\# 288110 \\
\hline M17 broth & $\mathrm{BD}$ & Cat\# 218561 \\
\hline Potassium Buffered Saline & Gibco & Cat\# 14190-144 \\
\hline $\begin{array}{l}0.45-\mu \mathrm{m} \text {-pore-size cellulose } \\
\text { acetate membrane }\end{array}$ & Sigma & Product\# WHA69012504 \\
\hline Acetic acid standard solution & Fisher Scientific & Cat\# A38S-500 \\
\hline Sulfuric acid & Fisher Scientific & Cat\# A300-500 \\
\hline Protease & Sigma & Product\# P5147 \\
\hline Magnesium sulfate & Fisher Scientific & Cat\# M65-500 \\
\hline RNase A & Thermo Scientific & Cat\# EN0531 \\
\hline DNase I & Invitrogen & Cat\# 18068015 \\
\hline a-amylase & Sigma & Cat\# 10065 \\
\hline Sodium cloride & Fisher Scientific & Cat\# S271-500 \\
\hline Tris-HCl & Calbiochem & Product\# 648310-M \\
\hline Sodium dodecyl sulfate & Sigma & Product\# L4509 \\
\hline 24-well plates & Fisher Scientific & Cat\# 12556006 \\
\hline Agarose & DOT Scientific Inc. & Cat\# DS170042 \\
\hline Pallet paint & VWR International & Cat\# 9049-3 \\
\hline Chow diet & LabDiet & Cat\# 5201 \\
\hline DpnI & Fisher Scientific & Cat\# FERFD1704 \\
\hline $\begin{array}{l}0.22 \mu \mathrm{m} \text { filter, Polyvinylidene fluoride } \\
{[\mathrm{PVDF}]}\end{array}$ & Milipore & Cat\# SLGVM33RS \\
\hline Sodium hydroxide & Fisher Chemical & Cat\# S318100 \\
\hline Methanol & Fisher Chemical & Cat\# A456-500 \\
\hline Formic acid & Fisher Chemical & Cat\# A11350 \\
\hline Chloramphenicol & Dot Scientific & Cat\# DSC61000-25 \\
\hline Erythromycin & Fisher Scientific & Cat\# BP920-25 \\
\hline Rifampicin & TCI Chemicals & R0079-25G \\
\hline Vancomycin & Chem-Impex & Cat\# 00315 \\
\hline Ethanol & KOPTEC & Cat\# V1016 \\
\hline $\mathrm{P}_{\text {sak }}$ Induction peptide & Peptide2.0 & $\begin{array}{l}\text { Sequence: } \\
\text { MAGNSSNFIHKIKQIFTHR }\end{array}$ \\
\hline $\begin{array}{l}\text { Choice Taq DNA polymerase master } \\
\text { mix }\end{array}$ & Denville Scientific & Cat\# CB4070-8 \\
\hline Phusion Hot Start polymerase II & Thermo Scientific & Cat\# F-549-L \\
\hline T4 DNA ligase & Thermo Scientific & Cat\# EL0011 \\
\hline Polynucleotide kinase & Thermo Scientific & Cat\# EK0031 \\
\hline dATP & Promega & Cat\# U120A \\
\hline Ampligase & Lucigen & Cat\# A32750 \\
\hline Sodium Hydroxide & Fisher Scientific & Cat\# S318-500 \\
\hline
\end{tabular}




\begin{tabular}{|l|l|l|}
\hline $\mathrm{HCl}$ & Ricca Chemical Company & Cat\# 3440-1 \\
\hline Critical Commercial Assay Kits & & \\
\hline Qubit dsDNA quantification kit & Invitrogen & Cat\# Q32853 \\
\hline Genomic DNA purification kit & Promega & Cat\# A1120 \\
\hline GeneJET PCR purification kit & Thermo Scientific & Cat\# K0701 \\
\hline Plasmid isolation kit & Promega & Cat\# A9340 \\
\hline $\begin{array}{l}\text { Experimental Models: } \\
\text { Organisms/Strains }\end{array}$ & \\
\hline C57BL/6J, Male & Jackson Laboratory & Cat\# 000664 \\
\hline Oligonucleotides & \multicolumn{2}{|l|}{} \\
\hline See Table S4 for primers used for this study & \\
\hline Recombinant DNA & & \\
\hline See Table S5 for plasmids used for this study & Ver. 11.0.0 \\
\hline Software and Algorithms & SAS & Ver. 4.2.1 \\
\hline JMP Pro & Visual Data Tolls Inc. & Ver. 10.1.7 \\
\hline Datagraph & Bruker & (Kumar et al., 2018) \\
\hline Bruker Hystar software & MEGA & \\
\hline
\end{tabular}

\section{EXPERIMENTAL MODEL AND SUBJECT DETAILS}

\section{Microbial Strains and Growth Conditions}

441 strains were cultured in De Man Rogosa Sharpe (MRS) medium (Difco, BD BioSciences). For in

442 vitro competition and biofilm formation experiments, we used filter-sterilized $(0.22 \mu \mathrm{m}$ PVDF

443 filter, Millipore) MRS that was adjusted to $\mathrm{pH} 4.0$ with $1 \mathrm{M} \mathrm{HCl}$. Unless stated otherwise, we

444 prepared bacterial cultures as follows: L. reuteri strains were incubated at $37^{\circ} \mathrm{C}$ under hypoxic

445 conditions $\left(5 \% \mathrm{CO}_{2}, 2 \% \mathrm{O}_{2}\right)$. The MRS agar plates were incubated for 24 hours for colony

446 counting. Escherichia coli EC1000 was used as general cloning host and cultured with aeration

447 at $37^{\circ} \mathrm{C}$ in lysogeny broth (LB, Teknova). Lactococcus lactis MG1363 harboring pJP042

448 (VPL2047) was cultured under static condition at $30^{\circ} \mathrm{C}$ in $\mathrm{M} 17$ broth, which contains glucose

$449(0.5 \%[\mathrm{w} / \mathrm{v}])$. Electrocompetent E. coli EC1000 were prepared as described in (Sambrook and

450 Russell, 2006). Electrocompetent L. reuteri cells were prepared as described in (Van Pijkeren 
451 and Britton, 2012). If applicable, MRS for L. reuteri was supplemented with $5 \mu \mathrm{g} / \mathrm{ml}$

452 erythromycin, $5 \mu \mathrm{g} / \mathrm{ml}$ chloramphenicol or $25 \mu \mathrm{g} / \mathrm{ml}$ rifampicin.

454 Mice

\section{Ethics statement}

All mouse experiments were performed in accordance with NIH guidelines, Animal

458 Welfare Act, and US federal law and were approved by the Application Review for Research

459 Oversight at Wisconsin (ARROW) committee and overseen by the Institutional Animal Care and

460 Use Committee (IACUC) under protocol ID M005149-RO1-A01. Conventional pathogen-free and

461 germ-free mice were housed at Animal Science and Laboratory of Animal Research Facilities

462 respectively at the University of Wisconsin-Madison.

Mice Strains and Husbandry

Twelve-week-old germ-free male B6 mice (C57BL/6J) were maintained in a controlled

466 environment in plastic flexible film gnotobiotic isolators with a 12 hours light cycle. Sterilized

467 food (standard chow, LabDiet 5001, St Louis, MO) and water were provided ad libitum.

\section{Reagents and Enzymes}

To amplify DNA fragments for cloning and screening, we used Phusion Hot Start DNA

471 Polymerase II (Thermo Scientific) and Taq DNA polymerase (Denville Scientific), respectively.

472 We used T4 DNA ligase (Thermo Scientific) for blunt-end ligations. If applicable, we treated

473 column purified (Thermo Scientific) PCR products with DpnI (Thermo Scientific) to remove 
474 plasmid template DNA. Phosphorylation of double stranded DNA fragments was performed with

475 T4 Polynucleotide Kinase (Thermo Scientific). Ligase Cycling Reactions (LCR) were performed 476 as described previously (Kok et al., 2014). Oligonucleotides and double-stranded DNA fragments 477 were synthesized by Integrated DNA Technologies (IDT), and are listed in Table S2.

479 METHOD DETAILS

\section{Construction of $L$. reuteri mutant strains}

482 Construction of suicide shuttle vectors for homologous recombination

To generate mutant strains in lactobacilli we used the counterselection plasmid pVPL3002

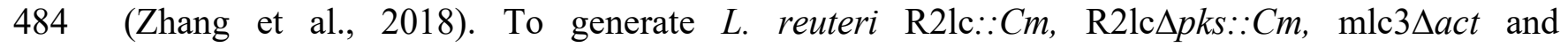
amplified by PCR (see Table S4 for oligonucleotides). We used following oligonucleotides; oVPL3113-3114 (upstream, R2lc::Cm), oVPL3115-3116 (downstream, R2lc::Cm), oVPL3194-

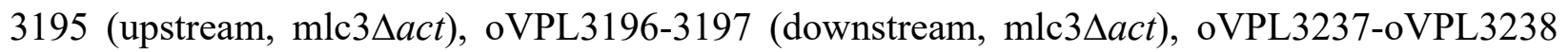



491 pVPL3002 backbone was amplified with oVPL187-oVPL188, purified (GeneJET PCR

492 Purification Kit, Thermo Scientific) and digested with DpnI. Purified amplicons were quantified

493 (Qubit, Life Technologies). The amplicons were mixed at equimolar quantities (0.25 pmol), 494 followed by phosphorylation, ethanol precipitation and LCR (Kok et al., 2014). Following LCR, 495 DNA was precipitated with Pellet Paint co-precipitant (VWR International), resuspended in $5 \mu 1$ 496 sterile water and transformed into electrocompetent E. coli EC1000 cells. By PCR, we screened 
497 for insertion of our target sequences using oligonucleotides that flank the multiple cloning site

498 (oVPL49-oVPL97). Finally, the integrity of deletion and insertion cassettes was determined by

499 Sanger sequencing. The resultant constructs were named as follow; VPL31130 (contains the

500 chloramphenicol insertion cassette for R2lc::Cm and R2lcspks::Cm), VPL31079 (contains act

501 deletion cassette for mlc3) and VPL31139 (contains act deletion cassette for DSM17938).

\section{Generating L. reuteri mutants by homologous recombination}

Three micrograms plasmid DNA was electroporated in electrocompetent $L$. reuteri cells.

505 For R21c:: $\mathrm{Cm}$, bacterial cells were plated on MRS agar containing $5 \mu \mathrm{g} / \mathrm{ml}$ chloramphenicol,

506 colonies were screened by PCR (oVPL13117-3118) to confirm double crossover event. For

$507 \mathrm{mlc} 3 \Delta a c t$, bacterial cells were plated on MRS agar containing $5 \mu \mathrm{g} / \mathrm{ml}$ erythromycin and colonies

508 were screened for single crossover (SCO) event by PCR with oligonucleotide mixtures oVPL3216-

509 oVPL3217-oVPL97 (upstream SCO) and oVPL3216-oVPL3217-oVPL49 (downstream SCO).

510 Following confirmation of SCO, bacterial cells were cultured for one passage in MRS broth

511 without antibiotic selection, and cells were plated on MRS agar plates containing $400 \mu \mathrm{g} / \mathrm{ml}$

512 vancomycin. For DSM17938 2 act, we used a fast-tract liquid-based approach, which does not

513 require isolation of single-crossover recombinants and cells are plated directly on MRS agar plates

514 containing $400 \mu \mathrm{g} / \mathrm{ml}$ vancomycin. Vancomycin-resistant colonies represent cells in which a

515 second homologous recombination event took place (Zhang at al. 2018). To confirm double

516 crossover (DCO), we performed PCR using oligonucleotides oVPL3216-oVPL3217 (for 


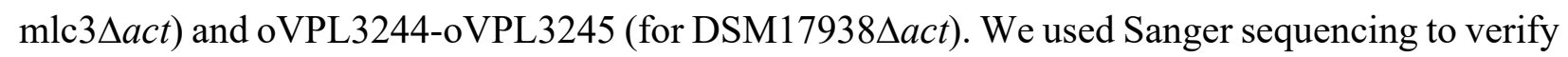

518 the integrity of the recombinant strains.

\section{Inactivation of $L$. reuteri 6475 acyltransferase by recombineering}

To inactivate the gene putatively encoding acyltransferase (LAR_1287) in L. reuteri 6475,

we applied single-stranded DNA recombineering using previously established procedure (Van

524 consecutive mismatches yielded, when incorporated, two in-frame stop codons (Van Pijkeren and

525 Britton, 2012). Electrocompetent L. reuteri 6475 cells harboring pJP042 (VPL2047) were

526 transformed with $100 \mu \mathrm{g}$ oVPL3166. To identify recombinants, we plated cells on MRS plates and

527 recombinant genotypes were identified by mismatch amplification mutation assay (MAMA) PCR

528 (Cha et al., 1992) using oligonucleotide combination oVPL3163-3164-3165. After colony

529 purification, the pure genotype recombinants were confirmed by MAMA-PCR and Sanger

530 sequencing. The resulted mutant strain was named as L. reuteri $6475 \Delta$ act. To cure pJP042, cells

531 were grown in plain MRS for two passages and plated on MRS agar. Then cells were inoculated

532 in MRS containing $5 \mu \mathrm{g} / \mathrm{ml}$ erythromycin to identify cells from which pJP042 was cured.

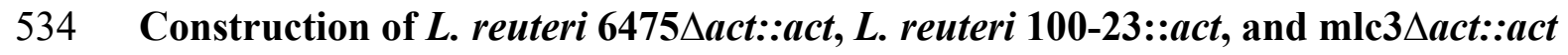

To complement act in L. reuteri 6475 , L. reuteri $100-23$, and L. reuteri mlc3, we cloned

536 the act gene from L. reuteri 6475 (oVPL3188- oVPL3189) into the pSIP411 backbone (oVPL399-

537 oVPL400). As described above, PCR products were quantified, DpnI treated and LCR reaction

538 was performed with bridging oligonucleotides (oVPL3220-3221) and transformed in E. coli

539 EC1000 cells. Insertion was confirmed by colony PCR (oVPL659- oVPL660) and the integrity of 
540 the DNA was confirmed by Sanger sequencing. One microgram of the resulting construct

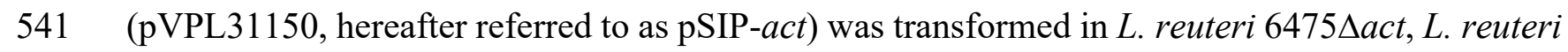

542 100-23 and L. reuteri mlc3 $\Delta$ act. Bacterial cells were plated on MRS agar containing $5 \mu \mathrm{g} / \mathrm{ml}$

543 erythromycin to identify cells containing pSIP-act overexpression plasmid (pVPL31150).

\section{Generating rifampicin resistant $L$. reuteri strains}

To enumerate the bacteria co-cultured with R21c:: $\mathrm{cm}$, we generated mutants that naturally

547 acquired mutations to yield resistance to rifampicin. Briefly, L. reuteri strains were grown in MRS

548 for 16 hours and plated on MRS agar containing $25 \mu \mathrm{g} / \mathrm{ml}$ rifampicin followed by 24 hours of

549 incubation at $37^{\circ} \mathrm{C}$ under hypoxic condition. Rifampicin resistant colonies were picked from

550 plates and after colony purification stored at $-80^{\circ} \mathrm{C}$.

\section{Whole Genome Sequencing}

Genomic DNA was isolated using the genomic DNA purification kit (Wizard, Promega), 553 and DNA concentrations were determined using the Qubit® (dsDNA High Sensitivity Assay Kit,

554 Life Technologies). Whole genome sequencing was performed at the University of Wisconsin-

555 Madison Biotechnology Center. Samples were prepared according to the Celero PCR Workflow 556 with Enzymatic Fragmentation (NuGEN). Quality and quantity of the finished libraries were 557 assessed using an Agilent bioanalyzer and Qubit ${ }^{\circledR}$ dsDNA HS Assay Kit, respectively. Libraries 558 were standardized to $2 \mathrm{nM}$. Paired end, $250 \mathrm{bp}$ sequencing was performed using the Illumina 559 NovaSeq6000. Images were analyzed using the standard Illumina Pipeline, version 1.8.2. 
Reads were assembled de novo using SPAdes (version 3.11.1) software. Assembled draft genomes were uploaded to National Center of Biotechnology Information (NCBI) (Zhang et al. accepted) and the Joint Genome Institute Integrated Microbial Genomes and Microbes (JGI-IMG)

565 database to perform comparative genome analyses. The web-based comparative genome database

567 strains that are resistant to R2lc (ATCC PTA6475 [named as MM4-1A in JGI-IMG], mlc3, DSM20016 and Lr4000).

We used L. reuteri JCM112 acyltransferase protein sequence (LAR_1287) as a query sequence to search the National Center for Biotechnology Information (NCBI) Nonredundant

571 protein sequence (nr) and JGI-IMG database to identify homologous among L. reuteri strains.

572 Partial protein sequences were excluded from the data set. Amino acid sequences of L. reuteri act 573 genes were aligned by using MUSCLE (Edgar, 2004), and we constructed the phylogenetic tree 574 with MEGA 7.0 software (Kumar et al. 2016).

\section{In vitro competition assay with $L$. reuteri strains}

L. reuteri strains were grown in MRS for 16 hours. The rifampicin resistant competition

578 strains were co-cultured with either R2lc::Cm or R2lc $\Delta p k s:: C m$ at optical density $\mathrm{OD}_{600}: 0.05$

579 (from each strain in co-culture) in a pre-warmed MRS broth ( $\mathrm{pH} 4.0)$. The co-cultures were then

580 incubated for 24 hours at $37^{\circ} \mathrm{C}$. After incubation, a serial dilution was performed and $100 \mu 1$ from 581 appropriate dilution was plated to MRS plates containing chloramphenicol $(5 \mu \mathrm{g} / \mathrm{ml})$ or rifampicin $582(25 \mu \mathrm{g} / \mathrm{ml})$. After 24 hours of incubation, we determined the competition ratios. 
L. reuteri $\mathrm{R} 21 \mathrm{c}, \mathrm{R} 2 \mathrm{lc} \Delta p k s$ and 100-23 cultures were inoculated into $2 \mathrm{ml}$ MRS broth at $\mathrm{OD}_{600}=0.1$ (0.05 from each strain if co-culture) in 24-well plates (Fisher Scientific) and incubated

587 for 24 hours. The culture supernatant was removed and bacterial biofilm was washed three times

588 with $1 \mathrm{ml}$ PBS. The adherent cells were scraped from the well and re-suspended in $2 \mathrm{ml}$ PBS.

589 For colony enumeration, the suspended cultures were plated on MRS plates containing

590 chloramphenicol $(5 \mu \mathrm{g} / \mathrm{ml})$ for $\mathrm{R} 2 \mathrm{lc}$ and $\mathrm{R} 2 \mathrm{lc} \Delta p k s$ or rifampicin $(25 \mu \mathrm{g} / \mathrm{ml})$ for $100-23$, and 591 incubated for 24 hours.

\section{In vivo competition experiment}

Germ-free B6 (C57BL/6J, male 12-week old, n=4-5mice/group) mice were maintained in

595 sterile biocontainment cages in the gnotobiotic animal facility at the University of Wisconsin-

596 Madison. Mice were colonized following a single oral gavage of $200 \mu \mathrm{L}$. reuteri cocktail in

597 PBS (1:1 ratio, $\left.\sim 2 \times 10^{8} \mathrm{CFU}\right)$. Each group was gavaged with a mixture of either L. reuteri

598 R2lc::Cm + competition strain or L. reuteri R2lc $\Delta p k s:: C m+$ competition strain. Twenty-four

599 hours following colonization, fecal samples were collected daily from individual mice to

600 determine the fecal CFUs. Fecal samples were homogenized and diluted in PBS followed by

601 plating on MRS-Cm and MRS-Rif. After 24 hours of incubation colonies were counted. At day

6027 , mice were sacrificed by $\mathrm{CO}_{2}$ asphyxiation and digesta from forestomach, jejunum, cecum and

603 colon were collected, weighed and re-suspended with PBS (100 mg/ml) to determine the CFUs

604 per $100 \mathrm{mg}$ content.

605

606

\section{Determination of peptidoglycan O'-acylation by HPLC}



with some modifications. After 16 hours of incubation, the cells were harvested by centrifugation at $5,000 \times g$ and $4{ }^{\circ} \mathrm{C}$ for $5 \mathrm{~min}$, washed twice with $10 \mathrm{mM}$ sodium phosphate buffer $(\mathrm{pH}$ 6.5) and

610 then resuspended in $50 \mathrm{ml}$ of water ( $\mathrm{pH} 5.5$ to 6.0 ). The cell suspension was boiled in an equal

611 volume of $8 \%(\mathrm{w} / \mathrm{v})$ sodium dodecyl sulfate (SDS, 4\% w/v final concentration) in $25 \mathrm{mM} \mathrm{SP}$

612 buffer ( $\mathrm{pH}$ 6.5) for 1 hour under reflux with stirring. Samples were centrifuged $(30,000 \times g)$ and

613 the SDS-insoluble PG was washed (5 times) with sterile double distilled $\mathrm{H}_{2} \mathrm{O}$ to completely

614 remove SDS and lyophilized. Lyophilized PG was dissolved in $4 \mathrm{ml}$ of 1:1 mixture of $10 \mathrm{mM}$ Tris-

$615 \mathrm{HCl}(\mathrm{pH} 6.5)$ and $10 \mathrm{mM} \mathrm{NaCl}$ and sonicated for $2 \mathrm{~min}$. The PG suspension was treated with 100

$616 \mu \mathrm{g} / \mathrm{ml} \alpha$-amylase (from Bacillus sp., Sigma), $10 \mu \mathrm{g} / \mathrm{ml}$ DNase I (Invitrogen), $50 \mu \mathrm{g} / \mathrm{ml}$ RNase A

617 (Thermo Scientific), and $20 \mathrm{mM} \mathrm{MgSO}_{4}$ solution and incubated overnight at $37^{\circ} \mathrm{C}$ with shaking.

618 The PG suspension was further treated with $200 \mu \mathrm{g} / \mathrm{ml}$ protease (from Streptomyces griseus,

619 Sigma) and incubated overnight at $37^{\circ} \mathrm{C}$ with shaking. Samples were then re-extracted by boiling 620 in $1 \%$ SDS for $40 \mathrm{~min}$, washed, lyophilized and stored at $-20^{\circ} \mathrm{C}$ until use.

621 For the analysis of acetate release from PG, lyophilized PG (20 mg) was dissolved in 150

$622 \mu \mathrm{l} \mathrm{ddH}_{2} \mathrm{O}$ and mixed with an equal volume of either $160 \mathrm{mM} \mathrm{NaOH}$ or $160 \mathrm{mM}$ sodium

623 phosphate buffer ( $\mathrm{pH}$ 6.5) and incubated overnight at $37^{\circ} \mathrm{C}$ with shaking. The peptidoglycan was

624 collected by centrifugation at $15,000 \times g$ for $20 \mathrm{~min}$. The supernatant was filtered through a $0.45-$

$625 \mu \mathrm{m}$-pore-size cellulose acetate membrane and quantitation of released acetate was carried out in

626 a Dionex UltiMate 3000 HPLC equipped with an LPG-3400 quaternary pump, a WPS-3000

627 analytical autosampler, and a DAD-3000 diode array detector. The filtered supernatants or 100

$628 \mu \mathrm{M}$ of acetic acid standard solution were injected onto a $300 \times 7.8 \mathrm{~mm}$ Rezex ${ }^{\mathrm{TM}}$ ROA-Organic 
Acid $\mathrm{H}^{+}(8 \%)$ column and eluted isocratically with $20 \mathrm{mM} \mathrm{H}_{2} \mathrm{SO}_{4}$ at $0.5 \mathrm{ml} \mathrm{min}^{-1}$. The column was maintained and $40^{\circ} \mathrm{C}$ and absorbance was monitored at $210 \mathrm{~nm}$.

\section{LC/MS Sample preparation}

An aliquot of $1.5 \mathrm{ml}$ from each of the cultures were collected in Eppendorf tubes and

634 centrifuged at $2152 \times g$ for $5 \mathrm{~min}$. The supernatants were collected and transferred to dram vials

635 and the cell pellets were incubated for 1 hour in $100 \mu \mathrm{l}$ methanol. Next, the samples were

636 centrifuged again and the methanol extracts were added to 1 dram vials. A Gilson GX-271 liquid

637 handling system was used to subject $900 \mu \mathrm{L}$ of the samples to automated solid phase extraction

638 (SPE). Extracts were loaded onto pre-conditioned (1 $\mathrm{ml} \mathrm{MeOH}$ followed by $\left.1 \mathrm{ml} \mathrm{H}_{2} \mathrm{O}\right)$ EVOLUTE

639 ABN SPE cartridges (25 mg absorbent mass, $1 \mathrm{ml}$ reservoir volume; Biotage, S4 Charlotte, NC).

640 Samples were subsequently washed using $\mathrm{H}_{2} \mathrm{O}(1 \mathrm{ml})$ to remove media components, and eluted

641 with $\mathrm{MeOH}(500 \mu \mathrm{L})$ directly into an LC/MS-certified vial.

\section{UHPLC/HRESI-qTOF-MS Analysis of Extracts}

LC/MS data were acquired using a Bruker MaXis ESI-qTOF mass spectrometer (Bruker, Billerica, MA) coupled with a Waters Acquity UPLC system (Waters, Milford, MA) with a PDA

646 detector operated by Bruker Hystar software, as previously described (Hou et al., 2012). Briefly,

647 a solvent system of $\mathrm{MeOH}$ and $\mathrm{H}_{2} \mathrm{O}$ (containing $0.1 \%$ formic acid) was used on an $\mathrm{RP} \mathrm{C}-18$ column

648 (Phenomenex Kinetex 2.6 $\mathrm{m}, 2.1 \times 100 \mathrm{~mm}$; Phenomenex, Torrance, CA) at a flow rate of 0.3

$649 \mathrm{ml} / \mathrm{min}$. The chromatogram method started with a linear gradient from $\mathrm{MeOH} / \mathrm{H}_{2} \mathrm{O}(10 \% / 90 \%)$

650 to $\mathrm{MeOH} / \mathrm{H}_{2} \mathrm{O}(97 \% / 3 \%)$ in $12 \mathrm{~min}$, then held for 2 min at $\mathrm{MeOH} / \mathrm{H}_{2} \mathrm{O}(97 \% / 3 \%)$. Full scan mass

651 spectra (m/z-150-1550) were measured in positive Electrospray Ionization (ESI) mode. The mass 
652 spectrometer was operated using the following parameters: capillary, $4.5 \mathrm{kV}$; nebulizer pressure,

6531.2 bar; dry gas flow, $8.0 \mathrm{~L} / \mathrm{min}$; dry gas temperature, $205^{\circ} \mathrm{C}$; scan rate, $2 \mathrm{~Hz}$. Tune mix (ESI-L

654 low concentration; Agilent, Santa Clara, CA) was introduced through a divert valve at the end of

655 each chromatographic run for automated internal calibration. Bruker Data Analysis 4.2 software

656 was used for analysis of chromatograms.

657

658

659 
<smiles>CCCCCCCCCC(=O)[C@H](C(=O)N[C@@H](CC(C)C)C(=O)N[C@@H](C)C(=O)N1CCC[C@H]1C(=O)N[C@H](C(=O)NC1CSCCNC1=O)C(C)C)C1CNC(=O)C1</smiles>

Streptococcus mutans mutanobactin A (PKS/NRPS)<smiles>CCCCCCCCCCCC(O)CC(=O)NCC(=O)O</smiles>

Bacteroides vulgatus commendamide (N-acyl-amide)

E<smiles>CCCCCCC/C=C/C(=O)N1C(O)=C(C=O)C(=O)[C@H]1CC(C)C</smiles>
Lactobacillus reuteri reutericyclin

G (tetramic acid)<smiles></smiles>

Escherichia coli colibactin (PKS/NRPS)<smiles>CC(C)CCCCCCCCCCC[C@H](O)CC(=O)N[C@H](COC(O)C1(CO)OC(O)C(O)C1O)[C@H](O)CCCCCCCCCCCC(C)C</smiles>

Bacteroides fragilis $\alpha$-galactosylceramide (sphingolipid)<smiles>[R]OC(=O)/C=C/C=C/C=C/C=C/C=C/C=C/c1ccc(O)c(F)c1</smiles>
Escherichia coli $\mathrm{APE}_{\mathrm{Ec}}$ (aryl polyene)

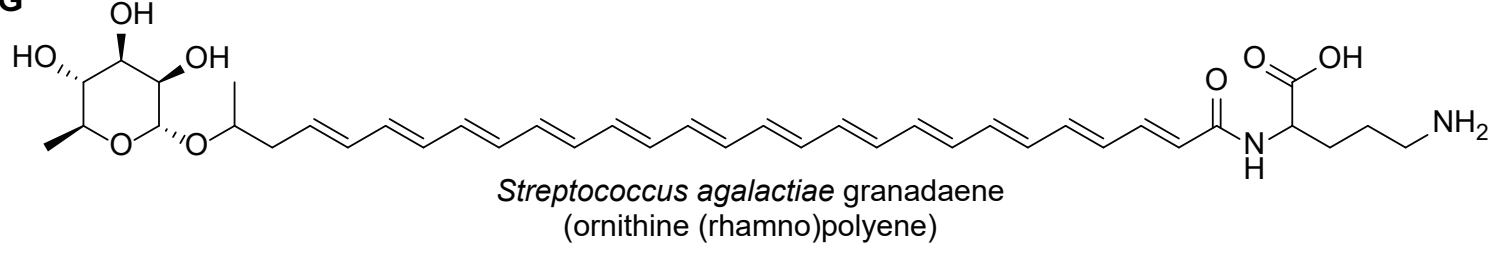

662 Figure s1. Structures of bioactive fatty acid-like, polyketide and NRPS/PKS hybrid compounds in bacteria from the gastrointestinal tract. Up to date, there are only seven

664 microbial metabolites from GI tract have been chemically identified. These are an antifungal

665 PKS/NRPS hybrid metabolite, Mutanobactin A produced by Steptococcus mutans, a genotoxin

666 PKS/NRPS hybrid metabolite, Colibactin produced by Escherichia coli; a G-Protein Coupled

667 Receptors (GPCR) agonist N-acyl-amide metabolite, Mutanobactin A, produced by Bacteroides

668 vulgatus; an invariant Natural Killer Cell (iNTK) activator sphingolipid metabolite, $\alpha$ - 
669 galactosylceramide, produced by Bacteroides fragilis; an antimicrobial tetramic acid metabolite,

670 Reutericyclin, produced by Lactobacillus reuteri; an antioxidant aryl polyene molecule, APEEC,

671 produced by Escherichia coli; a polyene ornithine compound, Granadaene, produced by

672 Streptococcus agalactiae. Related to Introduction.

673
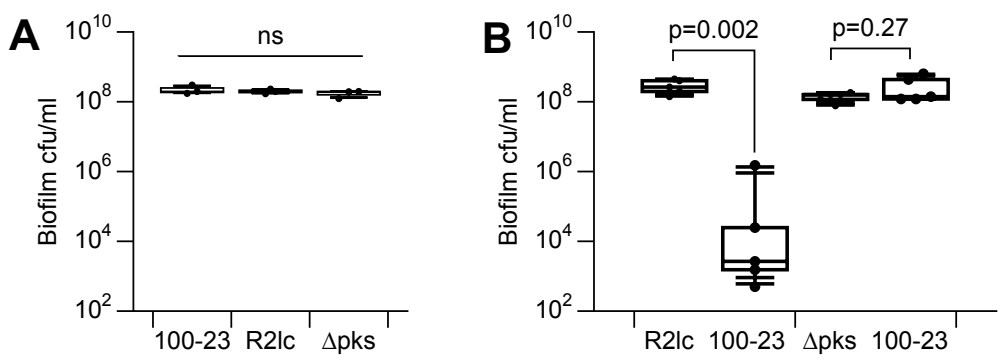

675 Figure s2. A polyketide synthase cluster in $L$. reuteri R2lc inhibits biofim formation of $L$.

reuteri 100-23. A) Quantification of the number of CFU in single and B) co-culture biofilm. For

677 box and whisker plots, the whiskers represent the maximum and minimal values, and the lower,

678 middle and upper line of the box represent first quartile, median and third quartile, respectively.

679 Circles represent individual data points. All data represent an average of at least three

680 independent experiments. Statistical significance was determined by Wilcoxon / Kruskal-Wallis

681 Tests $\mathrm{p}<0.05$ considered as significant. $\mathrm{p}=\mathrm{P}$ value. Related to Figure 1 . 


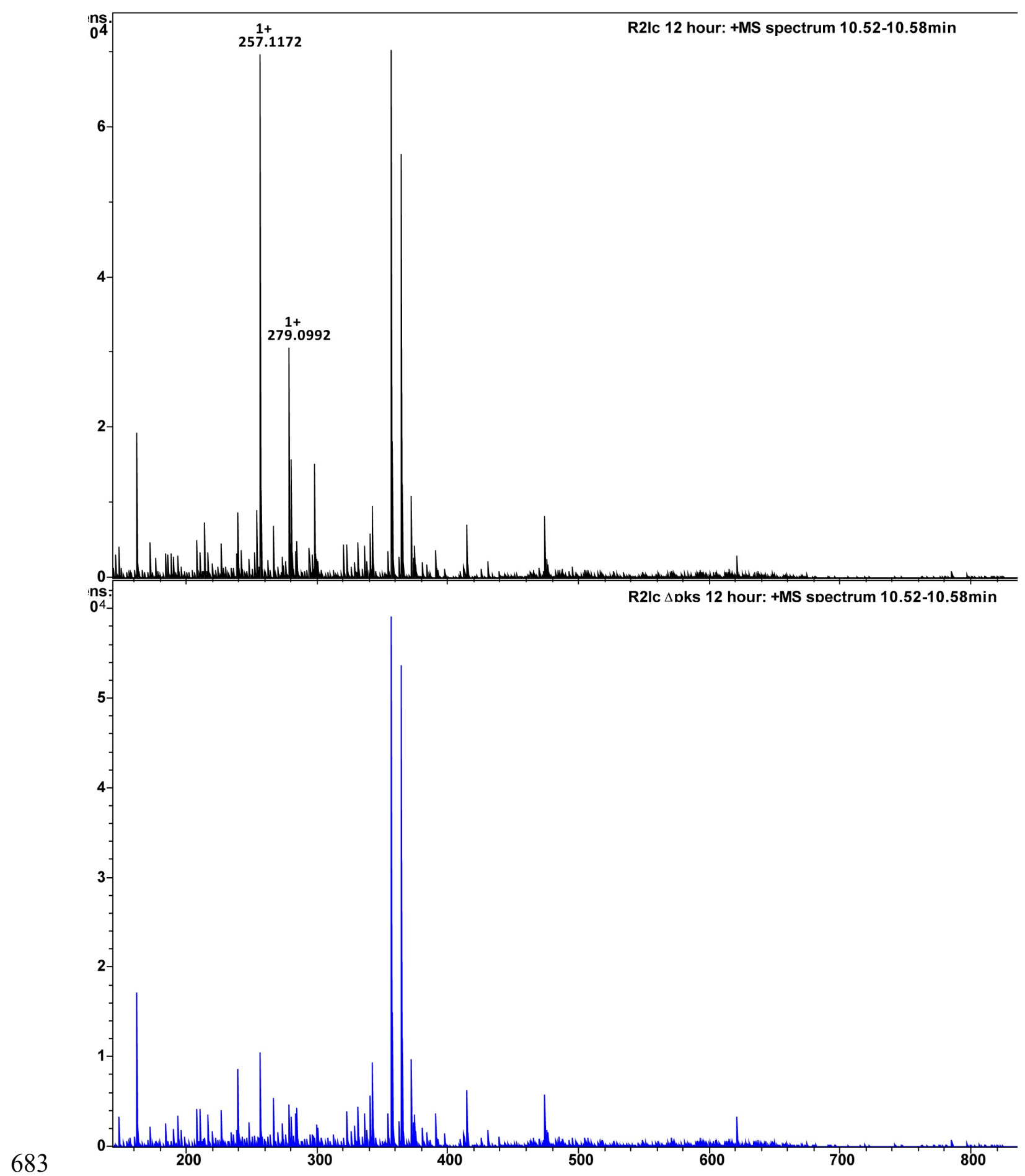

684 Figure s3. R2lc but not pks mutant produces unique compounds. The mass spectrum of the

685 peak between $10.52 \mathrm{~min}-10.58 \mathrm{~min}$ in the R2lc chromatogram at 12 hours clearly showed an ion 686 with $\mathrm{m} / \mathrm{zvalue}$ of 257.1172 as the $[\mathrm{M}+\mathrm{H}]+$ and 279.0092 as the corresponding $[\mathrm{M}+\mathrm{Na}]+$ which 
687 were absent in the corresponding 12-hour culture of $\Delta$ pks. Bruker Smart Formula algorithm,

688 which uses both the exact mass of the molecular ion and the isotopic pattern allowed accurate

689 determination of the molecular formula as $\mathrm{C}_{16} \mathrm{H}_{16} \mathrm{O}_{3}$. Related to Figure 1.

690

691 Table S1. Strains used for comparative genome analyses.

\begin{tabular}{clc}
\hline Strain Number & Strain & Sensitive/Resistant* \\
\hline 1 & CR & S \\
2 & $100-23$ & S \\
3 & L1604-1 & S \\
4 & ATCC53608 & S \\
5 & $3 c 6$ & S \\
6 & L1600-1 & S \\
7 & one-one & S \\
8 & rat19 & S \\
9 & JCM1081 & S \\
10 & I5007 & S \\
11 & $6799 j m-1$ & S \\
12 & lpuph & S \\
13 & CF48-3A1 & S \\
14 & 1366 & S \\
15 & N2J & S \\
16 & LR4020 & S \\
17 & SD2112 & S \\
18 & AD23 & S \\
19 & N4I & S \\
20 & $100-93$ & S \\
21 & PTA6475 & R \\
22 & DSM20016 & R \\
23 & mlc3 & R \\
24 & Lr4000 & R \\
\hline
\end{tabular}

*Sensitive/resistant phenotypes were determined based on statistical analyses shown in

Table S2. Unique genes in R2lc-resistat 6475, DSM20016 ${ }^{\mathrm{T}}$ and mlc3.

\begin{tabular}{lll}
\hline Locus Tag & Gene Name & Length (aa) \\
\hline Lreu_0435 & hypothetical protein & 69 \\
Lreu_0848 & holin, Cph1 family & 149 \\
Lreu_1143 & transcription regulator, XRE family & 67 \\
Lreu_1353 & hypothetical protein & 522 \\
Lreu_1362 & glycosyltransferase & 324 \\
Lreu_1368 & acyltransferase & 355 \\
Lreu_1869 & hypothetical protein & 175 \\
\hline
\end{tabular}

697 aa: amino acid. Related to Figure 4.

699 Table S3. Bacterial strains used in this study. 


\begin{tabular}{|c|c|c|c|c|}
\hline Genus and Species & Strain & $\begin{array}{c}\text { VPL } \\
\text { identifier }\end{array}$ & Description/ Origin & Source \\
\hline Escherichia coli & EC1000 & VPL1009 & Cloning host & $\begin{array}{l}\text { (Leenhouts et al., } \\
\text { 1996) }\end{array}$ \\
\hline $\begin{array}{l}\text { Lactococcus lactis ssp. } \\
\text { cremoris }\end{array}$ & MG1363 & VPL2005 & $\begin{array}{l}\text { L. lactis MG1363 } \\
\text { harboring pSIP411 }\end{array}$ & Laboratory stock \\
\hline Lactobacillus reuteri & R2lc & VPL1053 & Rat & $\begin{array}{l}\text { Siv Ahrné-JGI } \\
2716884882\end{array}$ \\
\hline Lactobacillus reuteri & R2lc:: $C m$ & VPL4231 & $\begin{array}{l}\text { Insertion of } \mathrm{Cm} \text { gene in } \\
\text { R2lc chromosome }\end{array}$ & This study \\
\hline Lactobacillus reuteri & $\mathrm{R} 2 \mathrm{lc} \Delta f u n:: C m$ & VPL4234 & $\begin{array}{l}\text { Insertion of } \mathrm{Cm} \text { gene in } \\
\mathrm{R} 2 \mathrm{lc} \Delta \text { fun chromosome }\end{array}$ & This study \\
\hline Lactobacillus reuteri & $\mathrm{R} 2 \mathrm{lc} \Delta p k s:: C m$ & VPL4209 & $\begin{array}{l}\text { Insertion of } \mathrm{Cm} \text { gene in } \\
\mathrm{R} 2 \mathrm{lc} \Delta p k s \text { chromosome }\end{array}$ & (Özçam et al., 2019) \\
\hline Lactobacillus reuteri & 6475 (pJP042) & VPL2047 & $\begin{array}{l}6475 \text { harboring pJP042 } \\
\text { plasmid }\end{array}$ & $\begin{array}{l}\text { (Van Pijkeren and } \\
\text { Britton, 2012) }\end{array}$ \\
\hline Lactobacillus reuteri & $6475 \Delta a c t$ & VPL4241 & $\begin{array}{l}\text { Deletion of act gene in } \\
6475\end{array}$ & This study \\
\hline Lactobacillus reuteri & $6475 \Delta a c t-\mathrm{Rif}^{\mathrm{R}}(\mathrm{pSIP} 411)$ & VPL31153 & $\begin{array}{l}6475 \Delta a c t-\mathrm{Rif}^{\mathrm{R}} \\
\text { harboring pSIP411 } \\
\text { plasmid }\end{array}$ & This study \\
\hline Lactobacillus reuteri & $6475 \Delta a c t: \because a c t-\mathrm{Rif}^{\mathrm{R}}$ & VPL4250 & $\begin{array}{l}6475 \Delta a c t-\mathrm{Rif}^{\mathrm{R}} \\
\text { harboring } \quad \text { pSIP-act } \\
\text { plasmid }\end{array}$ & This study \\
\hline Lactobacillus reuteri & $100-23$ & VPL1049 & Rat & JGI: 2500069000 \\
\hline Lactobacillus reuteri & $100-23-\mathrm{Rif}^{\mathrm{R}}$ & VPL4251 & 100-23 Rif resistant & This study \\
\hline Lactobacillus reuteri & $100-23-\mathrm{Rif}^{\mathrm{R}}(\mathrm{pSIP} 411)$ & VPL31155 & $\begin{array}{l}\text { 100-23- } \text { Rif }^{\mathrm{R}} \text { harboring } \\
\text { pSIP411 plasmid }\end{array}$ & This study \\
\hline Lactobacillus reuteri & $100-23:: a c t-\mathrm{Rif}^{\mathrm{R}}$ & VPL4249 & $\begin{array}{l}\text { Deletion of act gene in } \\
100-23, \text { Rif resistant }\end{array}$ & This study \\
\hline Lactobacillus reuteri & 6475 & VPL1014 & Human & BioGaia AB \\
\hline Lactobacillus reuteri & $6475-\mathrm{Rif}^{\mathrm{R}}$ & VPL4296 & 6475, Rif resistant & This study \\
\hline Lactobacillus reuteri & SD2112 & VPL1013 & Human & BioGaia AB \\
\hline Lactobacillus reuteri & SD2112- - if $^{\mathrm{R}}$ & VPL4297 & SD2112, Rif resistant & This study \\
\hline Lactobacillus reuteri & CSB7 & VPL1168 & Chicken & Jens Walter \\
\hline Lactobacillus reuteri & CSB7-Rif ${ }^{\mathrm{R}}$ & VPL4298 & CSB7, Rif resistant & This study \\
\hline Lactobacillus reuteri & KYE26 & VPL1162 & Chicken & Jens Walter \\
\hline Lactobacillus reuteri & KYE26- Rif $^{\mathrm{R}}$ & VPL4299 & KYE26, Rif resistant & This study \\
\hline Lactobacillus reuteri & LK159 & VPL1156 & Chicken & Jens Walter \\
\hline Lactobacillus reuteri & LK159- Rif $^{\mathrm{R}}$ & VPL4301 & LK159, Rif resistant & This study \\
\hline Lactobacillus reuteri & L4 & VPL1173 & Chicken & Jens Walter \\
\hline Lactobacillus reuteri & L4- $-\mathrm{Rif}^{\mathrm{R}}$ & VPL4302 & L4, Rif resistant & This study \\
\hline Lactobacillus reuteri & mouse 2 & VPL1070 & Mouse & (Frese et al., 2011) \\
\hline Lactobacillus reuteri & Mouse $2-\mathrm{Rif}^{\mathrm{R}}$ & VPL4252 & Mouse2, Rif resistant & This study \\
\hline Lactobacillus reuteri & N2J & VPL1052 & Rat & (Frese et al. 2011) \\
\hline Lactobacillus reuteri & N2J-- if $^{\mathrm{R}}$ & VPL4253 & N2J, Rif resistant & This study \\
\hline Lactobacillus reuteri & one-one & VPL1060 & Mouse & (Frese et al. 2011) \\
\hline Lactobacillus reuteri & one-one- $-\mathrm{Rif}^{\mathrm{R}}$ & VPL4254 & one-one, Rif resistant & This study \\
\hline Lactobacillus reuteri & ATCC 53608 & VPL1090 & Pig & $\begin{array}{l}\text { BioGaia AB EMBL } \\
\text { LN906634 }\end{array}$ \\
\hline Lactobacillus reuteri & ATCC 53608- Rif $^{R}$ & VPL4255 & $\begin{array}{l}\text { ATCC 53608, Rif } \\
\text { resistant }\end{array}$ & This study \\
\hline
\end{tabular}




\begin{tabular}{|c|c|c|c|c|}
\hline Lactobacillus reuteri & L1600-1 & VPL1064 & Mouse & (Frese et al. 2011) \\
\hline Lactobacillus reuteri & L1600-1- Rif $^{\mathrm{R}}$ & VPL4256 & L1600-1, Rif resistant & This study \\
\hline Lactobacillus reuteri & $\mathrm{N} 2 \mathrm{D}$ & VPL1067 & Rat & Siv Ahrné \\
\hline Lactobacillus reuteri & N2D- - Rif $^{R}$ & VPL4257 & N2D, Rif resistant & This study \\
\hline Lactobacillus reuteri & DSM17938 & VPL4171 & Human & BioGaia AB \\
\hline Lactobacillus reuteri & DSM17938- Rif $^{\mathrm{R}}$ & VPL4258 & DSM17938, Rif resistant & This study \\
\hline Lactobacillus reuteri & DSM17938 $\Delta a c t$ & VPL4313 & $\begin{array}{l}\text { Deletion of act gene in } \\
\text { DSM17938 }\end{array}$ & This study \\
\hline Lactobacillus reuteri & DSM17938 $\Delta a c t-\mathrm{Rif}^{\mathrm{R}}$ & VPL4315 & $\begin{array}{l}\text { DSM17938 } 1 a c t, \text { Rif } \\
\text { resistant }\end{array}$ & This study \\
\hline Lactobacillus reuteri & Lr4000 & VPL1071 & Mouse & BioGaia AB \\
\hline Lactobacillus reuteri & Lr4000- Rif $^{\mathrm{R}}$ & VPL4259 & Lr4000, Rif resistant & This study \\
\hline Lactobacillus reuteri & CF48-3A1 & VPL1086 & Human & $\begin{array}{l}\text { BioGaia AB- } \\
\text { JGI2502171173 }\end{array}$ \\
\hline Lactobacillus reuteri & CF48-3A1-Rif ${ }^{R}$ & VPL4260 & CF48-3A1, Rif resistant & This study \\
\hline Lactobacillus reuteri & L1604-1 & VPL1066 & Mouse & (Frese et al. 2011) \\
\hline Lactobacillus reuteri & L1604-1- Rif $^{\mathrm{R}}$ & VPL4261 & L1604-1, Rif resistant & This study \\
\hline Lactobacillus reuteri & $\mathrm{CR}$ & VPL1059 & Rat & (Frese et al. 2011) \\
\hline Lactobacillus reuteri & $\mathrm{CR}-\mathrm{Rif}^{\mathrm{R}}$ & VPL4262 & CR, Rif resistant & This study \\
\hline Lactobacillus reuteri & $\mathrm{mlc} 3$ & VPL1050 & Mouse & JGI: 2506381016 \\
\hline Lactobacillus reuteri & mlc3- - Rif $^{\mathrm{R}}$ & VPL4263 & mlc3, Rif resistant & JGI: 2506381016 \\
\hline Lactobacillus reuteri & $\mathrm{mlc} 3 \Delta a c t$ & VPL4246 & $\begin{array}{l}\text { Deletion of act gene in } \\
\text { mlc3 }\end{array}$ & This study \\
\hline Lactobacillus reuteri & mlc3 $3 a c t-\mathrm{Rif}^{\mathrm{R}}$ & VPL4308 & mlc3 $3 a c t$, Rif resistant & This study \\
\hline Lactobacillus reuteri & $\mathrm{mlc} 3 \Delta a c t-\mathrm{Rif}^{\mathrm{R}}(\mathrm{pSIP} 411)$ & VPL31177 & $\begin{array}{l}\text { mlc3 } \Delta a c t-\mathrm{Rif}^{\mathrm{R}}, \\
\text { harboring pSIP411 } \\
\text { plasmid }\end{array}$ & This study \\
\hline Lactobacillus reuteri & $\operatorname{mlc} 3 \Delta a c t:: a c t-\mathrm{Rif}^{\mathrm{R}}$ & VPL31165 & $\begin{array}{l}\text { mlc3 } \Delta a c t-\mathrm{Rif}^{\mathrm{R}} \\
\text { harboring pSIP-act } \\
\text { plasmid }\end{array}$ & This study \\
\hline Lactobacillus reuteri & $\mathrm{I} 5007$ & VPL1082 & Pig & JGI: 2554235423 \\
\hline Lactobacillus reuteri & I5007- Rif $^{\mathrm{R}}$ & VPL4264 & I5007, Rif resistant & This study \\
\hline Lactobacillus reuteri & Lr4020 & VPL1072 & Mouse & (Frese et al. 2011) \\
\hline Lactobacillus reuteri & Lr4020- Rif $^{\mathrm{R}}$ & VPL4265 & Lr4020, Rif resistant & This study \\
\hline Lactobacillus reuteri & Lp167-67 & VPL1085 & Pig & $\begin{array}{l}\text { BioGaia AB JGI } \\
2599185361\end{array}$ \\
\hline Lactobacillus reuteri & Lp167-67-Rif ${ }^{\mathrm{R}}$ & VPL4266 & Lp167-67, Rif resistant & This study \\
\hline Lactobacillus reuteri & N4I & VPL1063 & Rat & (Frese et al. 2011) \\
\hline Lactobacillus reuteri & N4I- Rif $^{R}$ & VPL4267 & N4I, Rif resistant & This study \\
\hline Lactobacillus reuteri & $3 \mathrm{c} 6$ & VPL1083 & Pig & JGI: 2599185333 \\
\hline Lactobacillus reuteri & $3 c 6-$ Rif $^{R}$ & VPL4268 & 3c6, Rif resistant & This study \\
\hline Lactobacillus reuteri & FUA3043 & VPL1062 & Rat & (Frese et al. 2011) \\
\hline Lactobacillus reuteri & FUA3043-Rif ${ }^{\mathrm{R}}$ & VPL4269 & FUA3043, Rif resistant & This study \\
\hline Lactobacillus reuteri & Rat 19 & VPL1069 & Rat & (Frese et al. 2011) \\
\hline Lactobacillus reuteri & Rat $19-\mathrm{Rif}^{\mathrm{R}}$ & VPL4270 & Rat 19, Rif resistant & This study \\
\hline Lactobacillus reuteri & 6799jm-1 & VPL1051 & Mouse & (Frese et al. 2011) \\
\hline Lactobacillus reuteri & 6799jm-1- $\mathrm{Rif}^{\mathrm{R}}$ & VPL4271 & 6799jm-1, Rif resistant & This study \\
\hline Lactobacillus reuteri & $100-93$ & VPL1047 & Mouse & (Frese et al. 2011) \\
\hline Lactobacillus reuteri & $100-93-$ Rif $^{\mathrm{R}}$ & VPL4272 & 100-93, Rif resistant & This study \\
\hline Lactobacillus reuteri & Lpuph-1 & VPL1056 & Mouse & JGI: 2506381017 \\
\hline Lactobacillus reuteri & Lpuph-1-Rif ${ }^{\mathrm{R}}$ & VPL4273 & Lpuph-1, Rif resistant & This study \\
\hline Lactobacillus reuteri & DSM 20016 & VPL1046 & Human & JGI: 640427118 \\
\hline
\end{tabular}




\begin{tabular}{|c|c|c|c|c|}
\hline Lactobacillus reuteri & DSM 20016-- if $^{R}$ & VPL4274 & DSM 20016, Rif resistant & This study \\
\hline Lactobacillus reuteri & $\mathrm{AD} 23$ & VPL1048 & Rat & (Frese et al. 2011) \\
\hline Lactobacillus reuteri & AD 23- Rif $^{R}$ & VPL4275 & $\mathrm{AD}$ 23, Rif resistant & This study \\
\hline Lactobacillus reuteri & $173 / 4$ & VPL1135 & Pig & Jens Walter \\
\hline Lactobacillus reuteri & $173 / 4-\mathrm{Rif}^{\mathrm{R}}$ & VPL4276 & 173/4, Rif resistant & This study \\
\hline Lactobacillus reuteri & $4 \mathrm{~S} 17$ & VPL1122 & Pig & (Frese et al. 2011) \\
\hline Lactobacillus reuteri & 4S17- Rif $^{\mathrm{R}}$ & VPL4277 & 4S17, Rif resistant & This study \\
\hline Lactobacillus reuteri & 1366 & VPL1115 & Chicken & Jens Walter \\
\hline Lactobacillus reuteri & $1366-\mathrm{Rif}^{\mathrm{R}}$ & VPL4278 & 1366, Rif resistant & This study \\
\hline Lactobacillus reuteri & JW2015 & VPL1126 & Pig & Jens Walter \\
\hline Lactobacillus reuteri & JW2015- Rif $^{\mathrm{R}}$ & VPL4279 & JW2015, Rif resistant & This study \\
\hline Lactobacillus reuteri & 32 & VPL1137 & Pig & Jens Walter \\
\hline Lactobacillus reuteri & $32-\mathrm{Rif}^{\mathrm{R}}$ & VPL4280 & 32, Rif resistant & This study \\
\hline Lactobacillus reuteri & $3 \mathrm{~S} 3$ & VPL1120 & Pig & Jens Walter \\
\hline Lactobacillus reuteri & $3 \mathrm{~S} 3-\mathrm{Rif}^{\mathrm{R}}$ & VPL4281 & 3S3, Rif resistant & This study \\
\hline Lactobacillus reuteri & $13 \mathrm{~S} 14$ & VPL1118 & Pig & Jens Walter \\
\hline Lactobacillus reuteri & $13 \mathrm{~S} 14-\mathrm{Rif}^{\mathrm{R}}$ & VPL4282 & 13S14, Rif resistant & This study \\
\hline Lactobacillus reuteri & LK150 & VPL1112 & Chicken & Jens Walter \\
\hline Lactobacillus reuteri & LK150- Rif $^{\mathrm{R}}$ & VPL4283 & LK150, Rif resistant & This study \\
\hline Lactobacillus reuteri & JCM 1081 & VPL1110 & Chicken & Jens Walter \\
\hline Lactobacillus reuteri & JCM 1081-Rif ${ }^{R}$ & VPL4284 & JCM 1081, Rif resistant & This study \\
\hline Lactobacillus reuteri & HW8 & VPL1166 & Chicken & Jens Walter \\
\hline Lactobacillus reuteri & HW8--Rif ${ }^{\mathrm{R}}$ & VPL4300 & HW8, Rif resistant & This study \\
\hline Lactobacillus reuteri & JW2019 & VPL1129 & Pig & Jens Walter \\
\hline Lactobacillus reuteri & JW2019--Rif ${ }^{\mathrm{R}}$ & VPL4286 & JW2019, Rif resistant & This study \\
\hline Lactobacillus reuteri & $1133(146 / 2)$ & VPL1133 & Pig & Jens Walter \\
\hline Lactobacillus reuteri & $1133(146 / 2)-\mathrm{Rif}^{\mathrm{R}}$ & VPL4287 & 1133, Rif resistant & This study \\
\hline Lactobacillus reuteri & CP415 & VPL1146 & Pig & Jens Walter \\
\hline Lactobacillus reuteri & CP415- Rif $^{\mathrm{R}}$ & VPL4288 & CP415, Rif resistant & This study \\
\hline Lactobacillus reuteri & 1063 & VPL1143 & Pig & Jens Walter \\
\hline Lactobacillus reuteri & $1063-$ Rif $^{\mathrm{R}}$ & VPL4289 & 1063, Rif resistant & This study \\
\hline Lactobacillus reuteri & 1068 & VPL1142 & Pig & Jens Walter \\
\hline Lactobacillus reuteri & $1068-\mathrm{Rif}^{\mathrm{R}}$ & VPL4291 & 1068, Rif resistant & This study \\
\hline Lactobacillus reuteri & 1048 & VPL1141 & Pig & Jens Walter \\
\hline Lactobacillus reuteri & $1048-\mathrm{Rif}^{\mathrm{R}}$ & VPL4292 & 1048, Rif resistant & This study \\
\hline Lactobacillus reuteri & 1013 & VPL1140 & Pig & Jens Walter \\
\hline Lactobacillus reuteri & $1013-\mathrm{Rif}^{\mathrm{R}}$ & VPL4293 & 1013, Rif resistant & This study \\
\hline Lactobacillus reuteri & 1704 & VPL1139 & Pig & Jens Walter \\
\hline Lactobacillus reuteri & $1704-\mathrm{Rif}^{\mathrm{R}}$ & VPL4294 & 1704, Rif resistant & This study \\
\hline Lactobacillus reuteri & FUA3048 & VPL1063 & Rat & (Frese et al. 2011) \\
\hline Lactobacillus reuteri & FUA3048-Rif ${ }^{\mathrm{R}}$ & VPL4295 & FUA3048, Rif resistant & This study \\
\hline
\end{tabular}

701 VPL: Van Pijkeren Laboratory strain identification number. pVPL: Van Pijkeren Laboratory

702 plasmid identification number. Rif ${ }^{\mathrm{R}}$ : rifampicin-resistant; act: acyltransferase; JGI: Joint Genome 703 Institute; Cm: Chloramphenicol; Rif: Rifampicin.

705 Table S4. Oligonucleotides used in this study.

\begin{tabular}{|l|l|l|}
\hline Oligonucleotide & Sequence (5'-3') & Target/Comment \\
\hline oVPL49 & acaatttcacacaggaaacagc & F. Insert screening of pVPL3002. \\
\hline oVPL97 & ccccattaagtgccgagtgc & R. Insert screening of pVPL3002. \\
\hline
\end{tabular}


bioRxiv preprint doi: https://doi.org/10.1101/2021.06.11.448121; this version posted June 12, 2021. The copyright holder for this preprint (which was not certified by peer review) is the author/funder. All rights reserved. No reuse allowed without permission.

\begin{tabular}{|c|c|c|}
\hline oVPL187 & taccgagctcgaattcactgg & R. amplifies pVPL3002 backbone. \\
\hline oVPL188 & atcctctagagtcgacctgc & F. amplifies pVPL3002 backbone. \\
\hline oVPL3113 & acgcacgacaggaagaatttg & $\begin{array}{l}\text { F. amplifies } \mathrm{u} / \mathrm{s} \text { flanking region of } \mathrm{CmR}^{+} \text {insertion } \\
\text { cassette. }\end{array}$ \\
\hline oVPL3114 & agactcgagcettgtggc & $\begin{array}{l}\text { R. amplifies } \mathrm{u} / \mathrm{s} \text { flanking region of } \mathrm{CmR}^{+} \text {insertion } \\
\text { cassette }\end{array}$ \\
\hline oVPL3115 & aagtacgaacgataatcagccc & $\begin{array}{l}\text { F. amplifies } \mathrm{d} / \mathrm{s} \text { flanking region of } \mathrm{CmR}^{+} \text {insertion } \\
\text { cassette. }\end{array}$ \\
\hline oVPL3116 & agccagtattatgacgggtc & $\begin{array}{l}\text { R. amplifies } \mathrm{d} / \mathrm{s} \text { flanking region of } \mathrm{CmR}^{+} \text {insertion } \\
\text { cassette }\end{array}$ \\
\hline oVPL2856 & agtgtcatggcgcattaacg & F. amplifies $\mathrm{CmR}^{+}$gene. \\
\hline oVPL2857 & ttataaaagccagtcattaggec & R. amplifies $\mathrm{CmR}^{+}$gene \\
\hline oVPL3166 & $\begin{array}{l}\text { tattaatgttattactagcaaacgaattaataaaatcctattaactag } \\
\text { gattaggatgcaacgatggaccaggataagca }\end{array}$ & L. reuteri 6475 act gene recombineering oligo. \\
\hline oVPL3163 & tgaacaaattcaggccaattatctgg & F. screening act gene \\
\hline oVPL3164 & tgtagttgtttggcgtcaggc & R. screening act gene \\
\hline oVPL3165 & cgttgcatcctaatcctagttaatag & MAMA oligonucleotide for $a c t$ gene \\
\hline oVPL659 & tgecccgttagttgaagaag & F. amplifies pSIP411 backbone. \\
\hline oVPL660 & attctgctccegeccttatg & R. amplifies pSIP411 backbone. \\
\hline oVPL3188 & ttaaggaattatcatcctaacaaatttattc & F. amplifies act gene in L. reuteri 6475 . \\
\hline oVPL3189 & atgcttaatagtaagagactccac & R. amplifies act gene in L. reuteri 6475 . \\
\hline oVPL3194 & acgatattgaatctttgcgactcc & $\begin{array}{l}\text { F. amplifies } \mathrm{u} / \mathrm{s} \text { flanking region of act gene in L. reuteri } \\
\text { mlc3. }\end{array}$ \\
\hline oVPL3195 & tagtggagtctcttactattaag & $\begin{array}{l}\text { R. amplifies } \mathrm{u} / \mathrm{s} \text { flanking region of act gene in } L \text {. reuteri } \\
\text { mlc3. }\end{array}$ \\
\hline oVPL3196 & aggaatattgtctggagtaagc & $\begin{array}{l}\text { F. amplifies d/s flanking region of act gene in L. reuteri } \\
\text { mlc3. }\end{array}$ \\
\hline oVPL3197 & ccattgtgactgtacatagtt & $\begin{array}{l}\text { R. amplifies } \mathrm{d} / \mathrm{s} \text { flanking region of act gene in L. reuteri } \\
\text { mlc3. }\end{array}$ \\
\hline oVPL3198 & $\begin{array}{l}\text { aaacgacggccagtgaattcgagctcggtaacgatattgaatctt } \\
\text { tgcgactccattatg }\end{array}$ & $\begin{array}{l}\text { LCR bridging oligonucleotide to ligate plasmid backbone } \\
+\mathrm{u} / \mathrm{s} \text { flanking region of mlc } 3 \Delta a c t \text { deletion cassette. }\end{array}$ \\
\hline oVPL3199 & $\begin{array}{l}\text { aattatgcttaatagtaagagactccactaaggaatattgtctgga } \\
\text { gtaagcttaggaat }\end{array}$ & $\begin{array}{l}\text { LCR bridging oligonucleotide to ligate } \mathrm{u} / \mathrm{s}+\mathrm{d} / \mathrm{s} \text { flanking } \\
\text { region of mlc } 3 \Delta a c t \text { deletion cassette. }\end{array}$ \\
\hline oVPL3200 & $\begin{array}{l}\text { gtagataataactatgtacagtcacaatggatcctctagagtcga } \\
\text { cetgcaggcatgcaa }\end{array}$ & $\begin{array}{l}\text { LCR bridging oligonucleotide to ligate } \mathrm{d} / \mathrm{s}+\text { plasmid } \\
\text { backbone of mlc } 3 \Delta \text { act deletion cassette. }\end{array}$ \\
\hline oVPL3216 & atcaccaccgaagagatacc & $\begin{array}{l}\text { F. L. reuteri mlc3 } 3 a c t \text { deletion cassette screening } \\
\text { oligonucleotide. }\end{array}$ \\
\hline oVPL3217 & agttgggtggataagtatgac & $\begin{array}{l}\mathrm{R} . \text { L. reuteri mlc3 } 3 a c t \text { deletion cassette screening } \\
\text { oligonucleotide. }\end{array}$ \\
\hline oVPL3220 & $\begin{array}{l}\text { ataaaatactattacaaggagattttagccatgcttaatagtaaga } \\
\text { gactccactacata }\end{array}$ & $\begin{array}{l}\text { Bridging oligonucleotide to ligate plasmid backbone }+ \\
\text { act gene for act gene overexpression cassettes. }\end{array}$ \\
\hline oVPL3221 & $\begin{array}{l}\text { aataaatttgttaggatgataattccttaagaattcggtacccegg } \\
\text { gttcgaaggcgeca }\end{array}$ & $\begin{array}{l}\text { Bridging oligonucleotide to ligate plasmid backbone }+ \\
\text { act gene for } \text { act gene overexpression cassettes. }\end{array}$ \\
\hline oVPL3237 & acgtgtctcctatgttaataccg & $\begin{array}{l}\text { F. amplifies u/s flanking region of act gene in L. reuteri } \\
\text { DSM17938. }\end{array}$ \\
\hline oVPL3238 & tataccaaattgtgctggat & $\begin{array}{l}\text { R. amplifies } \mathrm{u} / \mathrm{s} \text { flanking region of act gene in L. reuteri } \\
\text { DSM17938. }\end{array}$ \\
\hline oVPL3239 & aattattcgtataatagttgatcc & $\begin{array}{l}\text { F. amplifies d/s flanking region of act gene in L. reuteri } \\
\text { DSM17938. }\end{array}$ \\
\hline oVPL3240 & ccaactcacttgacccggta & $\begin{array}{l}\text { R. amplifies } \mathrm{d} / \mathrm{s} \text { flanking region of act gene in L. reuteri } \\
\text { DSM17938. }\end{array}$ \\
\hline oVPL3241 & $\begin{array}{l}\text { aaacgacggccagtgaattcgagctcggtaacgtgtctcctatg } \\
\text { ttaataccggggaaaa }\end{array}$ & $\begin{array}{l}\text { LCR bridging oligonucleotide to ligate plasmid backbone } \\
+\mathrm{u} / \mathrm{s} \text { flanking region of DSM17938 } \mathrm{act} \text { deletion } \\
\text { cassette. }\end{array}$ \\
\hline oVPL3242 & $\begin{array}{l}\text { actgtaactaatccagcacaatttggtataaattattcgtataatag } \\
\text { ttgatcctcttgt }\end{array}$ & $\begin{array}{l}\text { LCR bridging oligonucleotide to ligate } \mathrm{u} / \mathrm{s}+\mathrm{d} / \mathrm{s} \text { flanking } \\
\text { region of DSM } 17938 \Delta \text { act deletion cassette. }\end{array}$ \\
\hline oVPL3243 & $\begin{array}{l}\text { gttttcttttaccgggtcaagtgagttggatcctctagagtcgacc } \\
\text { tgcaggcatgcaa }\end{array}$ & $\begin{array}{l}\text { LCR bridging oligonucleotide to ligate } \mathrm{d} / \mathrm{s}+\text { plasmid } \\
\text { backbone of DSM17938 } \Delta \text { act deletion cassette. }\end{array}$ \\
\hline oVPL3244 & gaaattgttcgtcgctatgga & $\begin{array}{l}\text { F. L. reuteri DSM17938 } 1 \text { act deletion cassette screening } \\
\text { oligonucleotide. }\end{array}$ \\
\hline
\end{tabular}




\begin{tabular}{|l|l|l|}
\hline oVPL3245 & tcccagatttetggccaac & $\begin{array}{l}\text { R. L. reuteri DSM17938_act deletion cassette screening } \\
\text { oligonucleotide. }\end{array}$ \\
\hline
\end{tabular}

710 Table S5. Plasmids used in this study.

\begin{tabular}{|c|c|c|}
\hline Plasmid & Characteristic & Source \\
\hline pVPL3002 & pORI19 harboring L. reuteri derived ddIF258Y & (Zhang et al., 2018) \\
\hline pVPL31150 & pSIP411 harboring L. reuteri 6475 act gene & This Study \\
\hline pVPL2042 & $\mathrm{Em}^{\mathrm{R}}, \mathrm{pNZ8048}$ derivative. Cm marker was replaced by Em marker & (Zhang et al., 2018) \\
\hline pVPL31130 & $\begin{array}{l}\mathrm{Em}^{\mathrm{R}} \text {, derivative of vector pVPL3002 in which the } L . \text { reuteri } \\
\mathrm{R} 2 \mathrm{lc}:: C m \text { and R2lc } \Delta p k s:: C m \text { insertion cassette was cloned in the } \\
\text { MCS site. }\end{array}$ & This Study \\
\hline pVPL31079 & $\begin{array}{l}\mathrm{Em}^{\mathrm{R}} \text {, derivative of vector pVPL3002 in which the L. reuteri } \\
\text { mlc } 3 \Delta \text { act deletion cassette was cloned in the MCS site. }\end{array}$ & This Study \\
\hline pVPL31139 & $\begin{array}{l}\mathrm{Em}^{\mathrm{R}} \text {, derivative of vector pVPL3002 in which the } L . \text { reuteri } \\
\text { DSM17938 } \text { act deletion cassette was cloned in the MCS site. }\end{array}$ & This Study \\
\hline
\end{tabular}

711 pVPL: Van Pijkeren Laboratory plasmid identification number. $\mathrm{Em}^{\mathrm{R}}$ : Erythromycin-resistant; $\mathrm{Cm}^{\mathrm{R}}$ :

712 Chloramphenicol-resistant. Related to STAR Methods.

713 Table S6. Acyltransferase gene in L. reuteri strains

\begin{tabular}{|c|c|c|c|c|}
\hline Host & Host & Strain & Lineage & ACT_genes \\
\hline Rodent & Mouse (Mus musculus) & $480 \quad 44$ & $\mathrm{I}$ & No hits found \\
\hline Rodent & Mouse (Mus musculus) & $482 \_46$ & $\mathrm{I}$ & No hits found \\
\hline Rodent & Mouse (Mus musculus) & 484_39 & $\mathrm{I}$ & No hits found \\
\hline Rodent & Mouse & I49 & $\mathrm{I}$ & No hits found \\
\hline Rodent & Rat & L106 & $\mathrm{I}$ & Identities $=102 / 377(27 \%)$ \\
\hline Rodent & Rat & L107 & $\mathrm{I}$ & Identities $=102 / 377(27 \%)$ \\
\hline Rodent & Rattus norvegicus & L109 & $\mathrm{I}$ & Identities $=191 / 354(54 \%)$ \\
\hline Rodent & Rattus norvegicus & $\mathrm{L} 110$ & $\mathrm{I}$ & Identities $=191 / 354(54 \%)$ \\
\hline Rodent & Rattus norvegicus & L111 & $\mathrm{I}$ & Identities $=191 / 354(54 \%)$ \\
\hline Avian & Cape teal & L5 & $\mathrm{I}$ & No hits found \\
\hline Avian & Cape teal & L6 & $\mathrm{I}$ & No hits found \\
\hline Rodent & Mouse & lpuph1 & $\mathrm{I}$ & Identities $=63 / 246(26 \%)$ \\
\hline Rodent & Mouse (Mus musculus) & LR0 & $\mathrm{I}$ & No hits found \\
\hline Avian & Bird (Gallus gallus) & $\mathrm{P} 43$ & $\mathrm{I}$ & No hits found \\
\hline Rodent & Rat & TD1 & $\mathrm{I}$ & Identities $=102 / 377(27 \%)$ \\
\hline Human & Human & DSM 20016 & II & Identities $=352 / 355(99 \%)$ \\
\hline Human & Human (Homo sapiens) & IRT & II & Identities $=352 / 355(99 \%)$ \\
\hline Human & Human & JCM1112 & II & Identities $=352 / 355(99 \%)$ \\
\hline Human & Amaru indians & L26 & II & Identities $=193 / 354(55 \%)$ \\
\hline Human & Amaru indians & $\mathrm{L} 27$ & II & Identities $=193 / 354(55 \%)$ \\
\hline Human & Human & $\mathrm{L} 28$ & II & Identities $=352 / 355(99 \%)$ \\
\hline Human & Human & L29 & II & Identities $=352 / 355(99 \%)$ \\
\hline Human & Human & L30 & II & Identities $=351 / 355(99 \%)$ \\
\hline Human & Human & L31 & II & Identities $=351 / 355(99 \%)$ \\
\hline
\end{tabular}




\begin{tabular}{|c|c|c|c|c|}
\hline Human & Human & L32 & II & Identities $=352 / 355(99 \%)$ \\
\hline Human & Human & L33 & II & Identities $=352 / 355(99 \%)$ \\
\hline Human & Human & L37 & II & Identities $=352 / 355(99 \%)$ \\
\hline Human & Human (Homo sapiens) & MM2-3 & II & Identities $=352 / 355(99 \%)$ \\
\hline Human & Human (Homo sapiens) & MM4-1a & II & Identities $=352 / 355(99 \%)$ \\
\hline Rodent & Rat & $100-23$ & III & No hits found \\
\hline Rodent & Mouse & $103 \mathrm{~b}$ & III & Identities $=355 / 355(100 \%)$ \\
\hline Rodent & Mouse & $107 \mathrm{k}$ & III & No hits found \\
\hline Rodent & Mouse & $111 \mathrm{~b}$ & III & Identities $=355 / 355(100 \%)$ \\
\hline Rodent & Mouse & $609 d$ & III & No hits found \\
\hline Human & Human (Homo sapiens) & DS12_10 & III & No hits found \\
\hline Rodent & Mouse & L118 & III & No hits found \\
\hline Rodent & Mouse & L119 & III & No hits found \\
\hline Rodent & Mouse & L120 & III & Identities $=106 / 379(28 \%)$ \\
\hline Human & Amaru indians & $\mathrm{L} 25$ & III & No hits found \\
\hline Rodent & $\begin{array}{l}\text { Marmota } \\
\text { vancouveriensis }\end{array}$ & L92 & III & Identities $=355 / 355(100 \%)$ \\
\hline Rodent & Sourdough & LTH2584 & III & No hits found \\
\hline Rodent & Sourdough & LTH5448 & III & Identities $=193 / 354(55 \%)$ \\
\hline Rodent & Mouse & mlc3 & III & Identities $=355 / 355(100 \%)$ \\
\hline pig & Pig & ATCC 53608 & IV & Identities = 192/354 (54\%) \\
\hline pig & Pig & I5007 & IV & Identities $=107 / 384(28 \%)$ \\
\hline pig & Pig & KLR1001 & IV & Identities $=77 / 250(31 \%)$ \\
\hline pig & Pig & KLR2001 & IV & Identities $=192 / 354(54 \%)$ \\
\hline pig & Pig & KLR3002 & IV & No hits found \\
\hline Primate & Agile gibbon & L123 & IV & Identities $=85 / 321(26 \%)$ \\
\hline Primate & Lion-tailed Macaque & L125 & IV & Identities $=58 / 152(38 \%)$ \\
\hline Primate & Orangutan & L126 & IV & No hits found \\
\hline Primate & Japanese macaque & $\mathrm{L} 45$ & IV & No hits found \\
\hline Primate & Japanese macaque & L46 & IV & No hits found \\
\hline Primate & Japanese macaque & $\mathrm{L} 47$ & IV & No hits found \\
\hline Primate & Agile gibbon & $\mathrm{L} 48$ & IV & No hits found \\
\hline Primate & Agile gibbon & L49 & IV & No hits found \\
\hline Primate & Agile gibbon & L50 & IV & No hits found \\
\hline Primate & Gorilla & L55 & IV & No hits found \\
\hline Primate & Sulawesi macaque & L59 & IV & No hits found \\
\hline Primate & Mandrill & L60 & IV & No hits found \\
\hline Primate & Mandrill & L61 & IV & No hits found \\
\hline Primate & Mandrill & L62 & IV & No hits found \\
\hline Primate & Monkey & L68 & IV & No hits found \\
\hline Primate & Monkey & L69 & IV & No hits found \\
\hline Primate & Orangutan & L71 & IV & No hits found \\
\hline Primate & Orangutan & L72 & IV & No hits found \\
\hline Primate & Orangutan & L73 & IV & No hits found \\
\hline pig & Pig & $\operatorname{lp} 167-67$ & IV & No hits found \\
\hline pig & Pig & pg-3b & IV & No hits found \\
\hline pig & Pig & ZLR003 & IV & No hits found \\
\hline pig & Pig & $20-2$ & $\mathrm{~V}$ & Identities $=97 / 388(25 \%)$ \\
\hline pig & Pig & $3 \mathrm{c} 6$ & $\mathrm{~V}$ & No hits found \\
\hline
\end{tabular}




\begin{tabular}{|c|c|c|c|c|}
\hline Avian & Bird (Gallus gallus) & 1366 & VI & No hits found \\
\hline Avian & Gallus gallus & An166 & VI & Identities $=97 / 388(25 \%)$ \\
\hline Avian & Gallus gallus & An71 & VI & Identities $=97 / 388(25 \%)$ \\
\hline Human & Human (Homo sapiens) & CF48-3A & VI & Identities $=111 / 391(28 \%)$ \\
\hline Avian & Bird (Gallus gallus) & CSF8 & VI & No hits found \\
\hline Human & Homo sapiens & DS17_10 & VI & No hits found \\
\hline Avian & Gallus gallus & JCM1081 & VI & No hits found \\
\hline Avian & African spoonbiil & L1 & VI & Identities $=111 / 391(28 \%)$ \\
\hline Avian & Golden pheasant & $\mathrm{L} 10$ & VI & Identities $=82 / 272(30 \%)$ \\
\hline Avian & Golden pheasant & L11 & VI & Identities $=82 / 272(30 \%)$ \\
\hline Avian & Golden pheasant & $\mathrm{L} 12$ & VI & Identities $=82 / 272(30 \%)$ \\
\hline Avian & Poultry & L17 & VI & Identities $=97 / 388(25 \%)$ \\
\hline Avian & Quail & L19 & VI & Identities $=111 / 391(28 \%)$ \\
\hline Avian & Argus pheasent & L2 & VI & Identities $=197 / 354(56 \%)$ \\
\hline Avian & Quail & L20 & VI & Identities $=111 / 391(28 \%)$ \\
\hline Avian & Quail & $\mathrm{L} 21$ & VI & Identities $=111 / 391(28 \%)$ \\
\hline Avian & Turkey & L22 & VI & No hits found \\
\hline Avian & Turkey & L23 & VI & Identities $=352 / 355(99 \%)$ \\
\hline Avian & Turkey & L24 & VI & Identities $=111 / 391(28 \%)$ \\
\hline Avian & Argus pheasent & L3 & VI & Identities $=352 / 355(99 \%)$ \\
\hline Human & Human & L34 & VI & Identities $=111 / 391(28 \%)$ \\
\hline Human & Human & L35 & VI & Identities $=111 / 391(28 \%)$ \\
\hline Human & Human & L36 & VI & Identities $=111 / 391(28 \%)$ \\
\hline Avian & Argus pheasent & L4 & VI & Identities $=352 / 355(99 \%)$ \\
\hline Human & Png & $\mathrm{L} 43$ & VI & Identities $=153 / 353(43 \%)$ \\
\hline Avian & Francolin & L7 & VI & Identities $=111 / 391(28 \%)$ \\
\hline Avian & Francolin & L8 & VI & Identities $=111 / 391(28 \%)$ \\
\hline Avian & Francolin & L9 & VI & Identities $=111 / 391(28 \%)$ \\
\hline Human & Human (Homo sapiens) & M27U15 & VI & Identities $=111 / 391(28 \%)$ \\
\hline Human & Human (Homo sapiens) & MD-IIE-43 & VI & No hits found \\
\hline Human & Human (Homo sapiens) & MM34-4A & VI & Identities $=111 / 391(28 \%)$ \\
\hline Human & Human (Homo sapiens) & $\mathrm{RC}-14$ & VI & No hits found \\
\hline Human & Human (Homo sapiens) & SD2112 & VI & Identities $=111 / 391(28 \%)$ \\
\hline Rodent & Rat & L108 & VII & No hits found \\
\hline Rodent & Springhaas & L112 & VII & Identities $=193 / 354(55 \%)$ \\
\hline Rodent & Springhaas & L113 & VII & Identities $=193 / 354(55 \%)$ \\
\hline Rodent & Springhaas & L114 & VII & Identities $=193 / 354(55 \%)$ \\
\hline Rodent & Porqupine & L121 & VII & Identities $=252 / 355(71 \%)$ \\
\hline Human & Png & L38 & VII & No hits found \\
\hline Human & Png & L39 & VII & No hits found \\
\hline Human & Png & $\mathrm{L} 40$ & VII & No hits found \\
\hline Human & Png & L41 & VII & No hits found \\
\hline Human & Png & $\mathrm{L} 42$ & VII & No hits found \\
\hline Human & Png & L44 & VII & No hits found \\
\hline Primate & Black howler monkey & L51 & VII & Identities $=193 / 354(55 \%)$ \\
\hline Primate & Lion-tailed Macaque & L56 & VII & Identities $=109 / 384(28 \%)$ \\
\hline Primate & Lion-tailed Macaque & L57 & VII & No hits found \\
\hline Primate & Lion-tailed Macaque & L58 & VII & No hits found \\
\hline
\end{tabular}




\begin{tabular}{|c|c|c|c|c|}
\hline Primate & Patas monkey & L65 & VII & No hits found \\
\hline Primate & Monkey & $\mathrm{L} 70$ & VII & Identities $=254 / 355(72 \%)$ \\
\hline Rodent & Capy C & L85 & VII & No hits found \\
\hline Rodent & Capy C & L86 & VII & No hits found \\
\hline Rodent & Coendou prehensilis & L87 & VII & No hits found \\
\hline Rodent & Dasyprocta leporina & L88 & VII & No hits found \\
\hline Rodent & Dasyprocta leporina & L89 & VII & No hits found \\
\hline Primate & Black howler monkey & L124 & IX & Identities $=83 / 329(25 \%)$ \\
\hline Primate & Black howler monkey & L52 & IX & Identities $=83 / 329(25 \%)$ \\
\hline Primate & Black howler monkey & L53 & IX & Identities $=83 / 329(25 \%)$ \\
\hline Primate & Patas monkey & L66 & IX & No hits found \\
\hline Primate & Patas monkey & L67 & IX & No hits found \\
\hline Primate & Mandrill & L63 & Close to IX & No hits found \\
\hline Primate & Mandrill & L64 & Close to IX & No hits found \\
\hline Rodent & Apodemus agrarius & L77 & Close to L. reuteri & Identities $=106 / 384(28 \%)$ \\
\hline Rodent & Apodemus agrarius & L78 & Close to L. reuteri & Identities $=106 / 384(28 \%)$ \\
\hline Rodent & Apodemus agrarius & L79 & Close to L. reuteri & Identities $=106 / 384(28 \%)$ \\
\hline Rodent & Apodemus agrarius & L80 & Close to L. reuteri & Identities $=106 / 384(28 \%)$ \\
\hline
\end{tabular}

\section{References}

717 Aleti, G., Baker, J.L., Tang, X., Alvarez, R., Dinis, M., Tran, N.C., Melnik, A. V., Zhong, C.,

718 Ernst, M., Dorrestein, P.C., et al. (2019). Identification of the Bacterial Biosynthetic Gene

719 Clusters of the Oral Microbiome Illuminates the Unexplored Social Language of Bacteria during

720 Health and Disease. MBio 10.

721 Bonder, M.J., Kurilshikov, A., Tigchelaar, E.F., Mujagic, Z., Imhann, F., Vila, A.V., Deelen, P.,

722 Vatanen, T., Schirmer, M., Smeekens, S.P., et al. (2016). The effect of host genetics on the gut

723 microbiome. Nat. Genet. 48, 1407-1412.

724 Boon, E., Meehan, C.J., Whidden, C., Wong, D.H.-J., Langille, M.G.I., and Beiko, R.G. (2014).

725 Interactions in the microbiome: communities of organisms and communities of genes. FEMS

726 Microbiol. Rev. 38, 90-118.

727 Cha, R.S., Zarbl, H., Keohavong, P., and Thilly, W.G. (1992). Mismatch amplification mutation

728 assay (MAMA): Application to the c-H-ras gene. Genome Res. 2, 14-20. 
729 Cimermancic, P., Medema, M.H., Claesen, J., Kurita, K., Wieland Brown, L.C., Mavrommatis,

730 K., Pati, A., Godfrey, P.A., Koehrsen, M., Clardy, J., et al. (2014). Insights into secondary

731 metabolism from a global analysis of prokaryotic biosynthetic gene clusters. Cell 158, 412-421.

732 David, L.A., Maurice, C.F., Carmody, R.N., Gootenberg, D.B., Button, J.E., Wolfe, B.E., Ling,

733 A. V, Devlin, A.S., Varma, Y., Fischbach, M.A., et al. (2014). Diet rapidly and reproducibly

734 alters the human gut microbiome. Nature 505, 559-563.

735 Donia, M.S., Cimermancic, P., Schulze, C.J., Wieland Brown, L.C., Martin, J., Mitreva, M.,

736 Clardy, J., Linington, R.G., and Fischbach, M.A. (2014). A Systematic Analysis of Biosynthetic

737 Gene Clusters in the Human Microbiome Reveals a Common Family of Antibiotics. Cell 158,

$738 \quad 1402-1414$.

739 Duar, R.M., Frese, S.A., Lin, X.B., Fernando, S.C., Burkey, T.E., Tasseva, G., Peterson, D.A.,

740 Blom, J., Wenzel, C.Q., Szymanski, C.M., et al. (2017). Experimental Evaluation of Host

741 Adaptation of Lactobacillus reuteri to Different Vertebrate Species. Appl. Environ. Microbiol.

$74283, \mathrm{e} 00132-17$

743 Edgar, R.C. (2004). MUSCLE: Multiple sequence alignment with high accuracy and high

744 throughput. Nucleic Acids Res. 32, 1792-1797.

745 Edwards, K.F., Kremer, C.T., Miller, E.T., Osmond, M.M., Litchman, E., and Klausmeier, C.A.

746 (2018). Evolutionarily stable communities: a framework for understanding the role of trait

747 evolution in the maintenance of diversity. Ecol. Lett. 21, 1853-1868.

748 Frese, S.A., Benson, A.K., Tannock, G.W., Loach, D.M., Kim, J., Zhang, M., Oh, P.L., Heng,

749 N.C.K., Patil, P.B., Juge, N., et al. (2011). The evolution of host specialization in the vertebrate

750 gut symbiont Lactobacillus reuteri. PLoS Genet. 7.

751 Frese, S.A., MacKenzie, D.A., Peterson, D.A., Schmaltz, R., Fangman, T., Zhou, Y., Zhang, C., 
752 Benson, A.K., Cody, L.A., Mulholland, F., et al. (2013). Molecular Characterization of Host-

753 Specific Biofilm Formation in a Vertebrate Gut Symbiont. PLoS Genet. 9.

754 Le Gac, M., Plucain, J., Hindré, T., Lenski, R.E., and Schneider, D. (2012). Ecological and

755 evolutionary dynamics of coexisting lineages during a long-term experiment with Escherichia

756 coli. Proc. Natl. Acad. Sci. U. S. A. 109, 9487-9492.

757 Gruber, G., and Steglich, W. (2007). Calostomal, a polyene pigment from the gasteromycete

758 Colostoma cinnabarinum (Boletales). Zeitschrift Fur Naturforsch. - Sect. B J. Chem. Sci. 62,

759 129-131.

760 Ha, R., Frirdich, E., Sychantha, D., Biboy, J., Taveirne, M.E., Johnson, J.G., DiRita, V.J.,

761 Vollmer, W., Clarke, A.J., and Gaynor, E.C. (2016). Accumulation of Peptidoglycan $O$ -

762 Acetylation Leads to Altered Cell Wall Biochemistry and Negatively Impacts Pathogenesis

763 Factors of Campylobacter jejuni. J. Biol. Chem. 291, 22686-22702.

764 Herbrík, A., Corretto, E., Chroňáková, A., Langhansová, H., Petrásková, P., Hrdý, J., Čihák, M.,

765 Krištůfek, V., Bobek, J., Petř́íček, M., et al. (2020). A Human Lung-Associated Streptomyces sp.

766 TR1341 Produces Various Secondary Metabolites Responsible for Virulence, Cytotoxicity and

767 Modulation of Immune Response. Front. Microbiol. 10, 3028.

768 Hibbing, M.E., Fuqua, C., Parsek, M.R., and Peterson, S.B. (2010). Bacterial competition:

769 surviving and thriving in the microbial jungle. Nat. Rev. Microbiol. 8, 15-25.

770 Hiergeist, A., Gläsner, J., Reischl, U., and Gessner, A. (2015). Analyses of Intestinal Microbiota:

771 Culture versus Sequencing. ILAR J. 56, 228-240.

772 Hooper, L. V, Littman, D.R., Macpherson, A.J., and Program, M.P. (2015). Interactions between

773 the microbiota and the immune system. Science (80-. ). 336, 1268-1273.

774 Hou, Y., Braun, D.R., Michel, C.R., Klassen, J.L., Adnani, N., Wyche, T.P., and Bugni, T.S. 
775 (2012). Microbial Strain Prioritization Using Metabolomics Tools for the Discovery of Natural

776 Products. Anal. Chem. 84, 4277-4283.

777 Jacobson, A., Lam, L., Rajendram, M., Tamburini, F., Honeycutt, J., Pham, T., Van Treuren, W.,

778 Pruss, K., Stabler, S.R., Lugo, K., et al. (2018). A Gut Commensal-Produced Metabolite

779 Mediates Colonization Resistance to Salmonella Infection. Cell Host Microbe 24, 296-307.e7.

780 Kok, S. De, Stanton, L.H., Slaby, T., Durot, M., Holmes, V.F., Patel, K.G., Platt, D., Shapland,

781 E.B., Serber, Z., Dean, J., et al. (2014). Rapid and reliable DNA assembly via ligase cycling

782 reaction. ACS Synth. Biol. 3, 97-106.

783 Kumar, S., Stecher, G., Li, M., Knyaz, C., and Tamura, K. (2018). MEGA X: Molecular

784 Evolutionary Genetics Analysis across Computing Platforms. Mol. Biol. Evol. 35, 1547-1549.

785 Lee, A.J., Cadelis, M.M., Kim, S.H., Swift, S., Copp, B.R., and Villas-Boas, S.G. (2020).

786 Epipyrone A, a Broad-Spectrum Antifungal Compound Produced by Epicoccum nigrum ICMP

787 19927. Molecules 25, 5997.

788 Leenhouts, K., Buist, G., Bolhuis, A., Berge, A. ten, Kiel, J., Mierau, I., Dabrowska, M.,

789 Venema, G., and Kok, J. (1996). A general system for generating unlabelled gene replacements

790 in bacterial chromosomes. Mol. Gen. Genet. MGG 253, 217-224.

791 Li, J., Sang, M., Jiang, Y., Wei, J., Shen, Y., Huang, Q., Li, Y., and Ni, J. (2021). Polyene-

792 Producing Streptomyces spp. From the Fungus-Growing Termite Macrotermes barneyi Exhibit

793 High Inhibitory Activity Against the Antagonistic Fungus Xylaria. Front. Microbiol. 12, 649962.

794 Lin, X.B., Lohans, C.T., Duar, R., Zheng, J., Vederas, J.C., Walter, J., and Gänzle, M. (2015).

795 Genetic determinants of reutericyclin biosynthesis in Lactobacillus reuteri. Appl. Environ.

796 Microbiol. 81, 2032-2041.

797 Lin, X.B., Wang, T., Stothard, P., Corander, J., Wang, J., Baines, J.F., Knowles, S.C.L., 
Baltrūnaitè, L., Tasseva, G., Schmaltz, R., et al. (2018). The evolution of ecological facilitation within mixed-species biofilms in the mouse gastrointestinal tract. ISME J. 1. Martínez, I., Maldonado-Gomez, M.X., Gomes-Neto, J.C., Kittana, H., Ding, H., Schmaltz, R.,

801 Joglekar, P., Cardona, R.J., Marsteller, N.L., Kembel, S.W., et al. (2018). Experimental

802 evaluation of the importance of colonization history in early-life gut microbiota assembly. Elife

\section{7.}

804 Medema, M.H., Blin, K., Cimermancic, P., de Jager, V., Zakrzewski, P., Fischbach, M.A.,

805 Weber, T., Takano, E., and Breitling, R. (2011). antiSMASH: rapid identification, annotation and

806 analysis of secondary metabolite biosynthesis gene clusters in bacterial and fungal genome

807 sequences. Nucleic Acids Res. 39, W339-46.

808 Medema, M.H., Cimermancic, P., Sali, A., Takano, E., and Fischbach, M.A. (2014). A

809 Systematic Computational Analysis of Biosynthetic Gene Cluster Evolution: Lessons for

810 Engineering Biosynthesis. PLoS Comput. Biol. 10.

811 Moynihan, P.J., and Clarke, A.J. (2010). O-acetylation of peptidoglycan in gram-negative

812 bacteria: identification and characterization of peptidoglycan O-acetyltransferase in Neisseria

813 gonorrhoeae. J. Biol. Chem. 285, 13264-13273.

814 Murray, I.A., and Shaw, W. V. (1997). O-Acetyltransferases for chloramphenicol and other

815 natural products. Antimicrob. Agents Chemother. 41, 1-6.

816 Oh, J.H., and Van Pijkeren, J.P. (2014). CRISPR-Cas9-assisted recombineering in Lactobacillus

817 reuteri. Nucleic Acids Res. 42.

818 Oh, J.-H., Lin, X.B., Zhang, S., Tollenaar, S.L., Özçam, M., Dunphy, C., Walter, J.E., and

819 Pijkeren, J.-P. van (2019). Prophages in Lactobacillus reuteri are associated with fitness trade-

820 offs but can increase competitiveness in the gut ecosystem. Appl. Environ. Microbiol. 
821 Oh, P.L., Benson, A.K., Peterson, D.A., Patil, P.B., Moriyama, E.N., Roos, S., and Walter, J.

822 (2009). Diversification of the gut symbiont Lactobacillus reuteri as a result of host-driven

823 evolution. ISME J. 4, 377-387.

824 Özçam, M., and van Pijkeren, J.-P. (2019). Draft Genome Sequence of Aryl Hydrocarbon

825 Receptor Activator Strains Lactobacillus reuteri R2lc and 2010 . Microbiol. Resour. Announc. 8.

826 Özçam, M., Tocmo, R., Oh, J.H., Afrazi, A., Mezrich, J.D., Roos, S., Claesen, J., and van

827 Pijkeren, J.P. (2019). Gut symbionts Lactobacillus reuteri R2lc and 2010 encode a polyketide

828 synthase cluster that activates the mammalian aryl hydrocarbon receptor. Appl. Environ.

829 Microbiol. 85.

830 Van Pijkeren, J.P., and Britton, R.A. (2012). High efficiency recombineering in lactic acid

831 bacteria. Nucleic Acids Res. 40, 1-13.

832 Van Pijkeren, J.-P., Neoh, K.M., Sirias, D., Findley, A.S., and Britton, R.A. (2012). Exploring

833 optimization parameters to increase ssDNA recombineering in Lactococcus lactis and

834 Lactobacillus reuteri. Bioengineered 3, 209-217.

835 Ragland, S.A., and Criss, A.K. (2017). From bacterial killing to immune modulation: Recent

836 insights into the functions of lysozyme. PLoS Pathog. 13, e1006512.

837 Sambrook, J., and Russell, D.W. (2006). Transformation of E. coli by Electroporation. Cold

838 Spring Harb. Protoc. 2006, pdb.prot3933.

839 Sassone-Corsi, M., Nuccio, S.-P., Liu, H., Hernandez, D., Vu, C.T., Takahashi, A.A., Edwards,

840 R.A., and Raffatellu, M. (2016). Microcins mediate competition among Enterobacteriaceae in the

841 inflamed gut. Nature 540, 280-283.

842 Savage, D.C., Dubos, R., and Schaedler, R.W. (1968). The gastrointestinal epithelium and its

843 autochthonous bacterial flora. J. Exp. Med. 127, 67-76. 
844 Sender, R., Fuchs, S., and Milo, R. (2016). Revised Estimates for the Number of Human and

845 Bacteria Cells in the Body. PLoS Biol. 14, e1002533.

846 Snijders, A.M., Langley, S.A., Kim, Y.-M., Brislawn, C.J., Noecker, C., Zink, E.M., Fansler,

847 S.J., Casey, C.P., Miller, D.R., Huang, Y., et al. (2016). Influence of early life exposure, host

848 genetics and diet on the mouse gut microbiome and metabolome. Nat. Microbiol. 2, 16221.

849 Turnbaugh, P.J., Ridaura, V.K., Faith, J.J., Rey, F.E., Knight, R., and Gordon, J.I. (2009). The

850 effect of diet on the human gut microbiome: a metagenomic analysis in humanized gnotobiotic

851 mice. Sci. Transl. Med. 1, 6ra14.

852 Vaishnava, S., Yamamoto, M., Severson, K.M., Ruhn, K.A., Yu, X., Koren, O., Ley, R.,

853 Wakeland, E.K., and Hooper, L. V. (2011). The antibacterial lectin RegIII $\gamma$ promotes the spatial

854 segregation of microbiota and host in the intestine. Science (80-. ). 334, 255-258.

855 Veldhoen, M., Hirota, K., Westendorf, A.M., Buer, J., Dumoutier, L., Renauld, J.-C., and

856 Stockinger, B. (2008). The aryl hydrocarbon receptor links TH17-cell-mediated autoimmunity to

857 environmental toxins. Nature 453, 106-109.

858 Vollmer, W. (2008). Structural variation in the glycan strands of bacterial peptidoglycan. FEMS

859 Microbiol. Rev. 32, 287-306.

860 Walter, J., Britton, R.A., and Roos, S. (2011). Host-microbial symbiosis in the vertebrate

861 gastrointestinal tract and the Lactobacillus reuteri paradigm. Proc. Natl. Acad. Sci. 108, 4645-

8624652.

863 Youngblut, N.D., De La Cuesta-Zuluaga, J., Reischer, G.H., Dauser, S., Schuster, N., Walzer, C.,

864 Stalder, G., Farnleitner, A.H., and Ley, R.E. (2020). Large-Scale Metagenome Assembly

865 Reveals Novel Animal-Associated Microbial Genomes, Biosynthetic Gene Clusters, and Other

866 Genetic Diversity. 
867 Zarrinpar, A., Chaix, A., Yooseph, S., and Panda, S. (2014). Diet and feeding pattern affect the

868 diurnal dynamics of the gut microbiome. Cell Metab. 20, 1006-1017.

869 Zhang, S., Oh, J.-H., Alexander, L.M., Özçam, M., and Van Pijkeren, J.-P. (2018). D-Ala-D-Ala

870 ligase as a broad host-range counterselection marker in vancomycin-resistant lactic acid bacteria.

871 J. Bacteriol. JB.00607-17.

872 Zhao, W.T., Shi, X., Xian, P.J., Feng, Z., Yang, J., and Yang, X.L. (2021). A new fusicoccane

873 diterpene and a new polyene from the plant endophytic fungus Talaromyces pinophilus and their

874 antimicrobial activities. Nat. Prod. Res. 35, 124-130.

875 Zheng, J., Wittouck, S., Salvetti, E., Franz, C.M.A.P., Harris, H.M.B., Mattarelli, P., O’toole,

876 P.W., Pot, B., Vandamme, P., Walter, J., et al. (2020). A taxonomic note on the genus

877 Lactobacillus: Description of 23 novel genera, emended description of the genus Lactobacillus

878 beijerinck 1901, and union of Lactobacillaceae and Leuconostocaceae. Int. J. Syst. Evol.

879 Microbiol. 70, 2782-2858.

880 Zheng, Y., Valdez, P.A., Danilenko, D.M., Hu, Y., Sa, S.M., Gong, Q., Abbas, A.R., Modrusan,

881 Z., Ghilardi, N., de Sauvage, F.J., et al. (2008). Interleukin-22 mediates early host defense

882 against attaching and effacing bacterial pathogens. Nat. Med. 14, 282-289. 